\title{
Heterosynaptic $\mathrm{GABA}_{\mathrm{B}}$ Receptor Function within Feedforward Microcircuits Gates Glutamatergic Transmission in the Nucleus Accumbens Core
}

\author{
Kevin M. Manz, ${ }^{1,2}$ Andrew G. Baxley, ${ }^{6}$ Zack Zurawski, ${ }^{8}{ }^{\odot H e i d i ~ E . ~ H a m m, ~}{ }^{8}$ and $\odot^{\circ}$ Brad A. Grueter ${ }^{3,4,5,7}$ \\ ${ }^{1}$ Medical Scientist Training Program, ${ }^{2}$ Neuroscience Graduate Program, ${ }^{3}$ Department of Anesthesiology, ${ }^{4}$ Vanderbilt Brain Institute, ${ }^{5}$ Department of \\ Molecular Physiology and Biophysics, Vanderbilt University Medical Center, Nashville, Tennessee 37232, ${ }^{6}$ College of Arts and Sciences, ${ }^{7}$ Vanderbilt Center \\ for Addiction Research, and ${ }^{8}$ Department of Pharmacology, Vanderbilt University, Nashville, Tennessee 37232
}

Complex circuit interactions within the nucleus accumbens (NAc) facilitate goal-directed behavior. Medium spiny neurons (MSNs) mediate NAc output by projecting to functionally divergent brain regions, a property conferred, in part, by the differential projection patterns of D1- and D2 dopamine receptor-expressing MSNs. Glutamatergic afferents to the NAc direct MSN output by recruiting feedforward inhibitory microcircuits comprised of parvalbumin (PV)-expressing interneurons (INs). Furthermore, the $\mathrm{GABA}_{\mathrm{B}}$ heteroreceptor $\left(\mathrm{GABA}_{\mathrm{B}} \mathrm{R}\right)$, a $\mathrm{G}_{\mathrm{i} / \mathrm{o}}$-coupled G-protein-coupled receptor, is expressed at glutamatergic synapses throughout the mesolimbic network, yet its physiological context and synaptic mechanism within the NAc remains unknown. Here, we explored $G_{B B A} R$ function at glutamatergic synapses within PV-IN-embedded microcircuits in the NAc core of male mice. We found that $\mathrm{GABA}_{\mathrm{B}} \mathrm{R}$ is expressed presynaptically and recruits a noncanonical signaling mechanism to reduce glutamatergic synaptic efficacy at D1 $(+)$ and D1 $(-)$ (putative D2) MSN subtypes. Furthermore, PV-INs, a robust source of neuronal GABA in the NAc, heterosynaptically target $\mathrm{GABA}_{\mathrm{B}} \mathrm{R}$ to selectively modulate glutamatergic transmission onto D1 $(+)$ MSNs. These findings elucidate a new mechanism of feedforward inhibition and refine mechanisms by which $\mathrm{GABA}_{\mathrm{B}}$ heteroreceptors modulate mesolimbic circuit function.

Key words: feedforward inhibition; $\mathrm{GABA}_{\mathrm{B}}$; nucleus accumbens; parvalbumin interneurons; synaptic plasticity

Significance Statement

Glutamatergic transmission in the nucleus accumbens (NAc) critically contributes to goal-directed behaviors. However, intrinsic microcircuit mechanisms governing the integration of these synapses remain largely unknown. Here, we show that parvalbuminexpressing interneurons within feedforward microcircuits heterosynaptically target $G_{A B A}$ heteroreceptors $\left(G_{A B A} R\right)$ on glutamate terminals. Activation of presynaptically-expressed $\mathrm{GABA}_{\mathrm{B}} \mathrm{R}$ decreases glutamatergic synaptic strength by engaging a non-canonical signaling pathway that interferes with vesicular exocytotic release machinery. These findings offer mechanistic insight into the role of $\mathrm{GABA}_{\mathrm{B}}$ heteroreceptors within reward circuitry, elucidate a novel arm to feedforward inhibitory networks, and inform the growing use of $\mathrm{GABA}_{\mathrm{B}} \mathrm{R}$-selective pharmacotherapy for various motivational disorders, including addiction, major depressive disorder, and autism (Cousins et al., 2002; Kahn et al., 2009; Jacobson et al., 2018; Stoppel et al., 2018; Pisansky et al., 2019).

\section{Introduction}

The nucleus accumbens (NAc) is a critical node within the mesolimbic reward network implicated in maladaptive motivational

\footnotetext{
Received June 14, 2019; revised Sept. 3, 2019; accepted Sept. 22, 2019.

Author contributions: K.M.M. and B.A.G. designed research; K.M.M. and A.G.B. performed research; Z.Z. and H.E.H. contributed unpublished reagents/analytic tools; K.M.M. analyzed data; K.M.M. and B.A.G. wrote the paper.

This work was supported by National Institute on Drug Abuse Grant R01DA040630 (B.A.G). We thank members of the Grueter laboratory for their helpful comments and Dr. Roger Nicoll for generously reviewing and offering feedback on this project.

The authors declare no competing financial interests.

Correspondence should be addressed to Brad A. Grueter at brad.grueter@vumc.org.
}

states, including addiction and major depressive disorder (Lüscher and Malenka, 2011; Koob and Volkow, 2016). The NAc orchestrates goal-directed motivational behavior by integrating glutamatergic input from cortical and limbic brain structures (Kalivas, 2009; Turner et al., 2018a). Whereas experience-driven adaptations at glutamatergic inputs drive reward-related behavioral outcomes (Pascoli et al., 2014; LeGates et al., 2018), microcircuit mechanisms governing excitatory gain in the NAc remain

https://doi.org/10.1523/JNEUROSCI.1395-19.2019

Copyright $\odot 2019$ the authors 
largely unidentified. A putative gain control mechanism in the NAc are feedforward inhibitory microcircuits mediated by fastspiking parvalbumin (PV)-expressing interneurons (PV-INs). Glutamatergic afferents onto medium spiny projection neurons (MSNs), differentiated based on the expression of D1 $[\mathrm{D} 1(+)$ MSNs] or D2 dopamine receptors [D1(-) MSNs], collateralize onto PV-INs, which exert robust GABAergic control over MSN output (Wright et al., 2017; Scudder et al., 2018). PV-IN-directed feedforward inhibition gates NAc-dependent behavioral output by coordinating time-contingent changes in MSN action potential activity (Yu et al., 2017).

A potential candidate bridging glutamatergic transmission in the NAc to PV-IN-embedded feedforward microcircuits is the $\mathrm{GABA}_{\mathrm{B}}$ heteroreceptor $\left(\mathrm{GABA}_{\mathrm{B}} \mathrm{R}\right)$, a $\mathrm{G}_{\mathrm{i} / \mathrm{o}}$-coupled G-proteincoupled receptor (GPCR) expressed highly at synapses throughout mesolimbic and striatal networks (Lacey et al., 2005; Edwards et al., 2017). Clinical and preclinical studies of addiction indicate that baclofen (BAC), a selective $G_{A B A} R$ agonist, attenuates drug-seeking behavior, drug craving, and relapse (Hotsenpiller and Wolf, 2003; Kahn et al., 2009). In vivo BAC treatment attenuates cocaine-induced dopamine (DA) efflux into the NAc and is accompanied by decreased psychostimulant-induced hyperlocomotion, self-administration, and conditioned place preference (CPP; Roberts and Andrews, 1997; Li et al., 2001; Di Ciano and Everitt, 2003; Voigt et al., 2011). Congruent with these findings, $\mathrm{GABA}_{\mathrm{B}} \mathrm{R}$ activity recruits postsynaptic inward-rectifying $\mathrm{K}^{+}$ channels (Kir) channels in the ventral tegmental area to hyperpolarize NAc-projecting DA neurons, reducing functional mesoaccumbens DA output (Cruz et al., 2004; Labouèbe et al., 2007; Edwards et al., 2017). In the $\mathrm{NAc}, \mathrm{GABA}_{\mathrm{B}} \mathrm{R}$ is likely targeted by GABA from contiguous GABAergic circuits, such as PV-IN microcircuits, to elicit heterosynaptic changes in neurotransmission (Uchimura and North, 1991). In parallel with MSNs, PV-INs receive robust glutamatergic inputs that are required to drive activity-dependent feedforward inhibition (Yu et al., 2017; Scudder et al., 2018). Despite making up $0.5-1.0 \%$ of cells in the NAc, PV-INs extensively innervate MSN ensembles to regulate NAcdirected motivational output (Winters et al., 2012; Wright et al., 2017). For example, silencing PV-INs impairs amphetamineinduced locomotor sensitization and CPP, whereas strengthening of synapses onto PV-INs expedites cocaine self-administration (Yu et al., 2017; Wang et al., 2018). Although PV-INs critically regulate NAc-dependent motivational behavior, the synaptic repertoire used by these cells to entrain MSN output is unclear.

We hypothesized that PV-IN-embedded feedforward microcircuits regulate glutamatergic transmission in the NAc by heterosynaptically targeting $\mathrm{GABA}_{\mathrm{B}} \mathrm{R}$. Utilizing transgenic mice, optogenetics, and whole-cell patch-clamp electrophysiology, in combination with rigorous pharmacology, we demonstrate that presynaptic $\mathrm{GABA}_{\mathrm{B}} \mathrm{R}$ activity in the NAc core reduces glutamate release probability non-canonically in a SNAP-25-dependent manner that is distinct from similar $\mathrm{G}_{\mathrm{i} / \mathrm{o}}$-GPCRs in the NAc core. We find that PV-INs within feedforward inhibitory circuits are a heterosynaptic source of GABA regulating glutamatergic synapses by targeting presynaptically-expressed $\mathrm{GABA}_{\mathrm{B}} \mathrm{R}$. Congruent with the absence of autonomous PV-IN action potential activity, our findings indicate a lack of tonic $\mathrm{GABA}_{\mathrm{B}} \mathrm{R}$ activity, suggesting that heterosynaptic targeting of $\mathrm{GABA}_{\mathrm{B}} \mathrm{R}$ is activitydependent. Together, our results provide insight into mechanisms by which $\mathrm{GABA}_{\mathrm{B}} \mathrm{R}$ is recruited within a novel feedforward microcircuit to regulate glutamatergic transmission in the NAc.

\section{Materials and Methods}

Animals. Animals were bred and housed at Vanderbilt University Medical Center in accordance to IACUC. Male mice 8-12 weeks of age were used for all electrophysiological experiments. Mice were housed according to sex in groups of 2-5/cage on a $12 \mathrm{~h}$ light/dark cycle with ad libitum access to food and water. Breeding cages were given 5LOD chow (PicoLab, LabDiet; $28.7 \%$ protein, $13.4 \%$ fat, $57.9 \%$ carbohydrate) to improve litter viability. For all electrophysiological experiments, C57BL/6J mice were bred to harbor a BAC carrying the tdTomato fluorophore under control of the Drd1a (D1 receptor) promoter. For a subset of experiments, PV-IRES-Cre mice (Pvalb ${ }^{\text {tml(cre)Arbr}}$ ) were crossed with conditional channelrhodopsin-2 (ChR2) mice (Ai32(RCL-ChR2(H134R)/ EYFP) and Drdla-tdTomato mice, generating triple transgenic $\mathrm{PV}^{\mathrm{Cre}}$ cChR2-D1tdTomato (abbreviated PV ${ }^{\text {Cre }}$ ) mice. SNAP25 3 transgenic mice lacking the $\mathrm{G} \beta \gamma$-binding motif at the C-terminus of SNAP-25 and wild-type (WT) littermate controls were generously donated to our laboratory by the Heidi Hamm laboratory and colleagues (Vanderbilt University).

Electrophysiology. Whole-cell voltage-clamp recordings were obtained from D1tdTomato or PV ${ }^{\text {Cre }}$ mice, as described previously (Joffe and Grueter, 2016; Turner et al., 2018b). Mice were killed under isoflurane anesthesia. Briefly, parasagittal slices $(250 \mu \mathrm{M})$ containing the NAc core were prepared from whole brain tissue using a Leica Vibratome in oxygenated $\left(95 \% \mathrm{O}_{2} ; 5 \% \mathrm{CO}_{2}\right)$ ice-cold $\mathrm{N}$-methyl-D-glucamine (NMDG)based solution (in mM: $2.5 \mathrm{KCl}, 20 \mathrm{HEPES}, 1.2 \mathrm{NaH}_{2} \mathrm{PO}_{4}, 25$ glucose, 93 NMDG, $30 \mathrm{NaHCO}_{3}, 5.0$ sodium ascorbate, 3.0 sodium pyruvate, 10 $\mathrm{MgCl}_{2}$, and $0.5 \mathrm{CaCl}_{2}-2 \mathrm{H}_{2} \mathrm{O}$ ). Slices were then recovered in NMDGbased recovery solution for $10-15 \mathrm{~min}$ at $32^{\circ} \mathrm{C}$ before being transferred to a chamber containing artificial CSF (ACSF; in mM: $119 \mathrm{NaCl}, 2.5 \mathrm{KCl}$, $1.3 \mathrm{MgCl}_{2}-6 \mathrm{H}_{2} \mathrm{O}, 2.5 \mathrm{CaCl}_{2}-2 \mathrm{H}_{2} \mathrm{O}, 1.0 \mathrm{NaH}_{2} \mathrm{PO}_{4}-\mathrm{H}_{2} \mathrm{O}, 26.2 \mathrm{NaHCO}_{3}$, and 11 glucose). All experiments were performed using a Scientifica SliceScope Pro System with continuously-perfused $32^{\circ} \mathrm{C}$ ACSF at $2 \mathrm{ml} / \mathrm{min}$. MSNs in the NAc core were visualized using Scientifica PatchVision software and patched with 3-6 M $\Omega$ recording pipettes (P1000 Micropipette Puller) filled with a cesium $\left(\mathrm{Cs}^{+}\right)$-based internal solution [in mM: $120 \mathrm{CsMeSO}_{3}, 15 \mathrm{CsCl}, 8 \mathrm{NaCl}, 10 \mathrm{HEPES}, 0.2$ EGTA, 10 tetraethylammonium (TEA)-Cl, 4.0 Mg-ATP, 0.3 Na-GTP, 0.1 spermine, and 5.0 QX 314 bromide].

$\mathrm{D} 1(+)$ and D1(-) MSNs were differentiated according to the expression of the tdTomato fluorophore via $530 \mathrm{~nm}$ LED light. D1(-) MSNs were distinguished from interneuron cell types based on morphological (size, shape) and biophysical properties (e.g., capacitance, membrane resistance, and AMPAR decay kinetics). In SNAP25 3 and WT littermate mice, MSNs were unlabeled and carefully differentiated from other NAc cell types according to the above criteria. Isolated electricallyevoked EPSCs (eEPSCs) were performed in the continuous presence of $\mathrm{GABA}_{\mathrm{A}} \mathrm{R}$ antagonist, picrotoxin (PTX; $\left.50 \mu \mathrm{M}\right)$. In PV ${ }^{\text {Cre }}$ mice, opticallyevoked IPSCs (oIPSCs) were isolated by continuously superfusing panAMPAR antagonist, NBQX ( $5 \mu \mathrm{M})$, and NMDAR antagonist, D-APV (50 $\mu \mathrm{M}$ ), into the ACSF bath. Paired-pulse ratios (PPRs) were obtained within-experiment by delivering two $0.3 \mathrm{~ms}$ duration pulses with a $50 \mathrm{~ms}$ interstimulus interval and calculating the amplitude ratio of the second eEPSC to the first eEPSC ( eEPSC $_{2} /$ eEPSC $\left._{1}\right)$. Coefficient of variance $(\mathrm{CV})$ analysis was conducted within-experiment by calculating $\sigma / \mu$ of PSC amplitudes during specified time intervals. To assess cannabinoid receptor type-1 $\left(\mathrm{CB}_{1} \mathrm{R}\right)$ short-term plasticity, depolarization-induced suppression of excitation (DSE) was performed by depolarizing the postsynaptic cell from -70 to $+40 \mathrm{mV}$ for $10 \mathrm{~s}$. eEPSCs obtained preand post-DSE were obtained with a $5 \mathrm{~s}$ interstimulus interval to capture synaptically-evoked short-term plasticity. To quantify the kinetics of the $\mathrm{Cd}^{2+}$-induced blockade of eEPSC amplitude, each experiment was fit with a nonlinear curve to capture the specific time point, $T$, at which eEPSC amplitude was $50 \%$ from baseline. $T$ was then subtracted from the time point coinciding with the end of the baseline to obtain $T_{1 / 2}$. mEPSC analysis was performed with Clampfit 10.4 using a stringent best-fit template obtained from preliminary 10 min recording bouts in $\mathrm{D} 1(+)$ and D1(-) MSNs. Each recording bout yielded a rise/d time $(\leq 3 \mathrm{~ms})$ and amplitude $(\geq 5 \mathrm{pA})$ selection criteria that was reflected in the overall 
template score. Series resistance $\left(R_{\mathrm{S}}\right)$ was monitored continuously during all experiments, with $>20 \%$ change in $R_{\mathrm{S}}$ resulting in the omission of that experiment. Execution of experimental protocols, stimulus control, and data collection were accomplished using Molecular Devices pClamp 10 Analysis software. Monitoring electrical properties of cells was achieved using AxoPatch 500B MultiClamp amplifier and Axon Digidata 1550 low-noise data acquisition digitizer. Responses were filtered at 2 $\mathrm{kHz}$ and digitized at $10 \mathrm{kHz}$. Optical stimulation of ChR2-expressing cells was achieved using a CoolLED pE-100 LED excitation system. Four hundred and eighty nanometers of light at variable intensities (5-40\%) was pulsed through the $40 \times$ high-power objective at $0.1 \mathrm{~Hz}$ with a duration of $0.3-0.5 \mathrm{~ms}$.

Pharmacology. (RS)-Baclofen, SCH 50911, CGP 7930, forskolin, $\mathrm{CdCl}_{2}, \mathrm{BaCl}_{2}, \mathrm{LY} 341495$, LY 379268, $\omega$-conotoxin GVIA( $\omega$-CTx), $\omega$-agatoxin IVA( $\omega$-AgTx), WIN 55,212-2, H89, 4-aminopyridine, and tiagabine were purchased from Tocris Bioscience. PTX and $\mathrm{N}$ ethylmaleimide were purchased from Sigma-Aldrich.

Statistics and data analysis. Electrophysiological experiments were analyzed using Clampfit 10.4 and GraphPad Prism v7.0. Changes in baseline eEPSC/oIPSC amplitude, CV, and PPR were calculated by comparing mean values during 5 min intervals specified in each time course to baseline PPR and CV values. A depression was defined as a significant difference in eEPSC or oIPSC amplitude from baseline calculated during the time interval specified in the recording. For specific oIPSC experiments at PV-IN-to-MSN synapses, cells were rendered BAC-responsive (+) if BAC application resulted in a significant depression in oIPSC amplitude from baseline. To separate $\mathrm{BAC}(+)$ from $\mathrm{BAC}(-)$ negative synapses, a threshold criterion was set at $>35 \%$ depression from baseline. Long-term depression (LTD) was defined as a significant difference in eEPSC or oIPSC amplitude from baseline that persisted in the presence of $\mathrm{GABA}_{\mathrm{B}} \mathrm{R}$ antagonist, $\mathrm{SCH}$ 50911. After obtaining each dataset, Shapiro-Wilk tests were performed to assess normality. Data depicted in Figures 1-8 were determined to be normally distributed. Thus, paired or unpaired $t$ tests were used to analyze statistical differences between datasets. Sidak's post hoc analyses were used for analyses requiring multiple comparisons. Figure 9 depicts data that were determined to not be normally distributed, consistent with separable populations of PV-IN-to-MSN synapses. Power analyses were performed with preliminary data during the acquisition of each new dataset. The sample size obtained from each power analysis calculation was then compared with sample sizes reported in the literature for similar experiments. Errors bars depicted in figures represent SEM. For all analyses, $\alpha$ was set as 0.05 , with $p$ values $<\alpha$ indicating a statistically significant difference.

\section{Results}

Presynaptic $\mathrm{GABA}_{\mathrm{B}} \mathrm{R}$ activity reduces synaptic efficacy at glutamatergic synapses onto D1(+) and D1(-) MSNs in the NAc core

To determine whether $\mathrm{GABA}_{\mathrm{B}} \mathrm{R}$ activity modulates synaptic efficacy at glutamatergic synapses in the NAc core, we performed whole-cell voltage-clamp recordings in ex vivo brain slice preparations from D1tdTomato BAC transgenic reporter mice. Expression of the red-florescent protein, tdTomato (tdT), is driven by the D1 dopamine receptor promoter, with tdT-expressing cells indicating D1 $(+)$ MSNs and tdT-lacking cells indicating D1(-) MSNs (putative D2 receptor-expressing MSNs; Fig. 1A; Lim et al., 2012; Rothwell et al., 2014; Joffe and Grueter, 2016; Kashima and Grueter, 2017; Turner et al., 2018b). Electricallyevoked EPSCs (eEPSCs) were isolated by incorporating $\mathrm{GABA}_{\mathrm{A}}$ receptor $\left(\mathrm{GABA}_{\mathrm{A}} \mathrm{R}\right)$ antagonist, PTX $(50 \mu \mathrm{M})$, into the ACSF bath. Following a stable $10 \mathrm{~min}$ eEPSC baseline, $\mathrm{GABA}_{\mathrm{B}} \mathrm{R}$ agonist, $\mathrm{BAC}(3 \mu \mathrm{M})$, was superfused into the bath for $10 \mathrm{~min}$, resulting in a robust depression in eEPSC amplitude at D1 $(+)$ and D1(-) MSNs that was indistinct between cell types (Fig. 1B-E; $\mathrm{D} 1(+) \mathrm{BAC}: 35.7 \pm 4.1 \%, n=7, p<0.0001$; D1 $(-) \mathrm{BAC}: 32.9 \pm$ $3.8 \%, n=7, p<0.0001)$. Subsequent application of $\mathrm{GABA}_{\mathrm{B}} \mathrm{R}$ antagonist, SCH $50911(5 \mu \mathrm{M})$, reversed the BAC-induced depression to baseline at $\mathrm{D} 1(+)$ and $\mathrm{D} 1(-) \mathrm{MSN}$, indicating a lack of $\mathrm{GABA}_{\mathrm{B}} \mathrm{R}$-induced LTD $\left(\mathrm{GABA}_{\mathrm{B}} \mathrm{R}-\mathrm{LTD}\right)$ at local glutamatergic synapses (Fig. $1 B-E$; $\mathrm{D} 1(+)$ : $103.5 \pm 6.9 \%, n=6, p=0.61$; D1 $(-): 99.6 \pm 1.7 \%, n=6, p=0.80)$.

We next examined whether $\mathrm{GABA}_{\mathrm{B}} \mathrm{R}$ activity modulates pharmacologically-isolated NMDA receptor (NMDAR)-mediated eEPSCs obtained at $+40 \mathrm{mV}$ in $\mathrm{D} 1(+)$ and D1 $(-)$ MSNs. Indeed, BAC application resulted in a robust decrease in NMDAR eEPSC amplitude at $\mathrm{D} 1(+)$ and $\mathrm{D} 1(-)$ MSN synapses (Fig. $1 G, H ; \mathrm{D} 1(+): 35.29 \pm 10.2 \%, n=4, p=0.0052 ; \mathrm{D} 1(-): 36.27 \pm$ $9.36 \%, n=6, p=0.0007)$. To determine whether synapses onto $\mathrm{D} 1(+)$ and $\mathrm{D} 1(-)$ MSNs are differentially sensitive to $\mathrm{GABA}_{\mathrm{B}} \mathrm{R}$ activation, we obtained a dose-response curve with BAC concentrations ranging from $200 \mathrm{nM}-10 \mu \mathrm{M}$. Whereas higher concentrations $(3-10 \mu \mathrm{M})$ resulted in an equivalent decrease in eEPSC amplitude at both MSN subtypes, lower concentrations (200$600 \mathrm{nM})$ resulted in a greater decrease in eEPSC amplitude at $\mathrm{D} 1(+)$ than D1(-) MSN synapses (Fig. 1F; $200 \mathrm{~nm}, \mathrm{D} 1(+)$ : $55.55 \pm 4.80 \%, n=5$; D1 $(-): 72.46 \pm 4.35 \%, n=6 ; 600 \mathrm{nM}$, $\mathrm{D} 1(+): 43.10 \pm 5.72 \%, n=5 ; \mathrm{D} 1(-): 59.82 \pm 2.76 \%, n=4 ; 3$ $\mu \mathrm{M}$, reported above; $10 \mu \mathrm{M}, \mathrm{D} 1(+): 18.21 \pm 4.16 \%, n=3$; D1(-): $21.38 \pm 1.29 \%, n=4$; two-way ANOVA, effect of MSN subtype: $\left.F_{(1,28)}=8.688, p=0.006\right)$. Prior application of SCH 50911 did not alter basal eEPSC amplitude and completely blocked the BAC-induced depression at both MSN subtypes (Fig. $1 I, D 1(+): 99.39 \pm 3.95 \%, n=5, p=0.74 ; 100.66 \pm 3.78 \%, n=$ $4, p=0.21)$.

$\mathrm{GABA}_{\mathrm{B}} \mathrm{R}$ is expressed throughout the mesolimbic reward network with diverse presynaptic and postsynaptic sites of action (Cruz et al., 2004; Pitman et al., 2014; Edwards et al., 2017). Given that $\mathrm{GABA}_{\mathrm{B}} \mathrm{R}$ is presynaptically-expressed at MSN-to-MSN collateral synapses (Dobbs et al., 2016), we performed multiple electrophysiological measurements to determine the synaptic locus of $\mathrm{GABA}_{\mathrm{B}} \mathrm{R}$ at glutamatergic synapses in the NAc core. We first assessed changes in paired-pulse ratio (PPR) and coefficient of variance $(\mathrm{CV})$, metrics which inversely correlate with presynaptic neurotransmitter release probability. BAC significantly increased PPR and $\mathrm{CV}$ at $\mathrm{D} 1(+)$ and $\mathrm{D} 1(-) \mathrm{MSN}$ synapses that returned to baseline in the presence of SCH 50911 (Fig. $2 A, B$; PPR $=\mathrm{D} 1(+)$ baseline: $1.19 \pm 0.04, \mathrm{D} 1(+) \mathrm{BAC}: 1.8 \pm 0.2, \mathrm{D} 1(+) \mathrm{SCH}: 1.16 \pm$ $0.08, n=8$, one-way RM ANOVA, drug effect: $F_{(2,21)}=13.85$, $p=0.0001$; Sidak's post hoc analysis, BAC: $p=0.004$; D1 $(-)$ baseline: $0.97 \pm 0.07, \mathrm{D} 1(-) \mathrm{BAC}: 1.69 \pm 0.20, \mathrm{D} 1(-) \mathrm{SCH}$ : $1.02 \pm 0.08, n=8$, one-way RM ANOVA, drug effect: $F_{(2,21)}=$ $11, p=0.0005$; Sidak's post hoc analysis, BAC: $p=0.008$; $\mathrm{CV}=$ $\mathrm{D} 1(+)$ baseline: $0.06 \pm 0.01, \mathrm{D} 1(+)$ BAC: $0.51 \pm 0.07, \mathrm{D} 1(+)$ SCH: $0.09 \pm 0.02, n=8$, one-way RM ANOVA, drug effect: $F_{(2,18)}=37.48, p<0.0001$; Sidak's post hoc analysis, BAC: $p=$ 0.001; D1 $(-)$ baseline: $0.05 \pm 0.01, \mathrm{D} 1(-)$ BAC: $0.55 \pm 0.05$, $\mathrm{D} 1(+) \mathrm{SCH}: 0.13 \pm 0.03, n=8$, one-way RM ANOVA, drug effect: $F_{(2,18)}=68.36, p<0.0001$; Sidak's post hoc analysis, BAC: $p=0.001)$. This experiment performed in a Cs ${ }^{+} /$TEA-free, $\mathrm{K}^{+}$. loaded internal solution resulted in a similar change in PPR and $\mathrm{CV}$ without altering holding current or membrane resistance, suggesting a presynaptic change in glutamate release probability that is unaccompanied by a postsynaptic $\mathrm{K}^{+}$conductance (data not shown). We next examined the effects of BAC on tetrodotoxin (500 nM)-insensitive miniature EPSCs (mEPSCs). Consistent with a presynaptic site of action, BAC significantly decreased mEPSC frequency without altering mEPSC amplitude (Fig. $2 C-F$; mEPSC frequency $=\mathrm{D} 1(+)$ baseline: $1.38 \pm 0.022 \mathrm{~Hz}$, $\mathrm{D} 1(+)$ BAC: $0.82 \pm 0.08 \mathrm{~Hz}, n=9, p=0.027$; D1 $(-)$ baseline: 
A

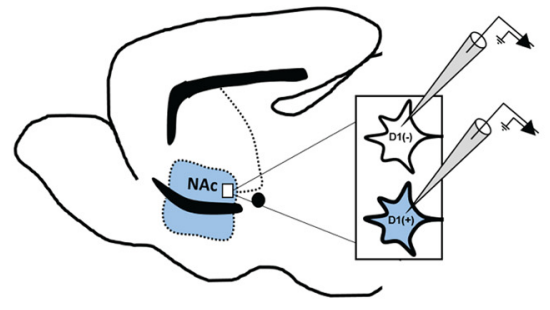

D

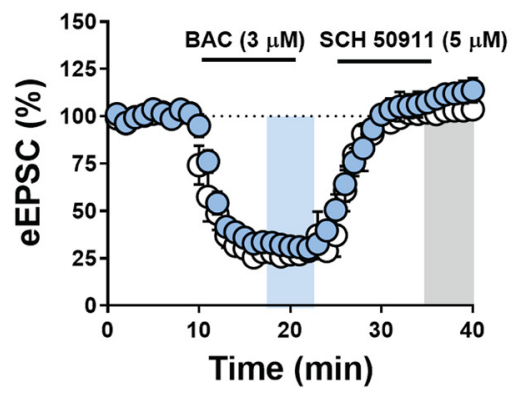

D1(+) MSN

B
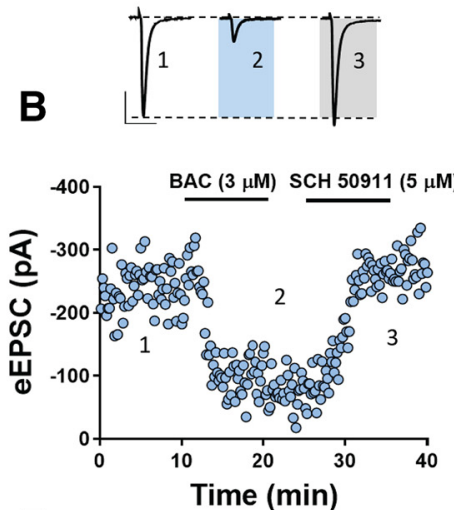

E

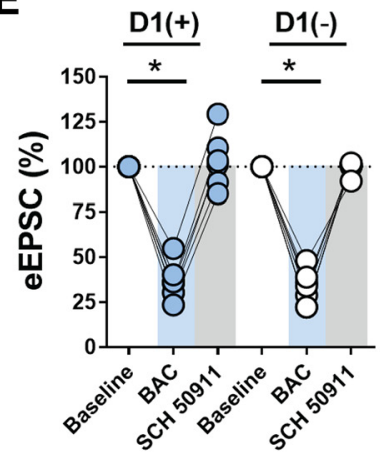

O D1(-) MSN

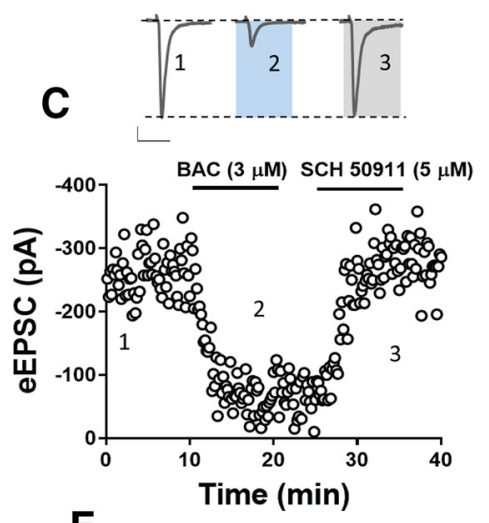

F
G

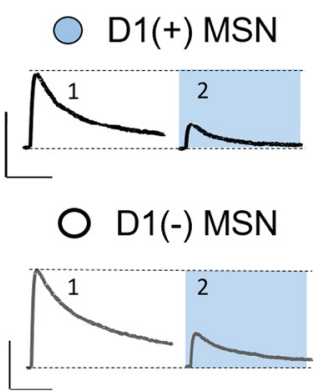

H

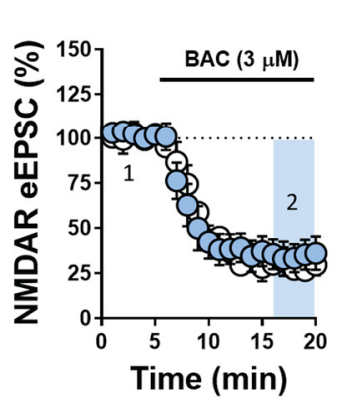

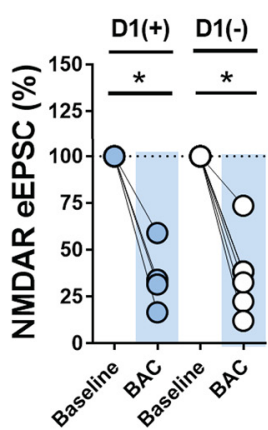

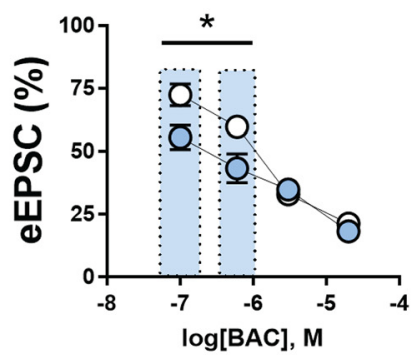

I

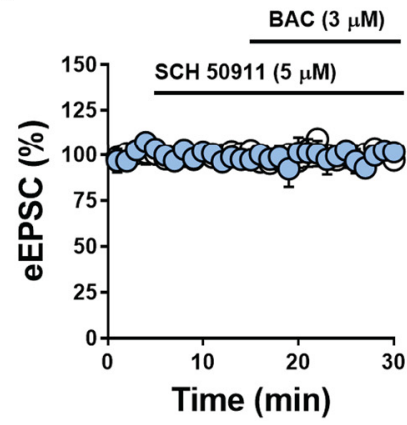

Figure 1. $G_{A B A} R$ activity reduces synaptic efficacy at glutamatergic synapses onto D1 (+) and D1( -$)$ MSNs in the NAc core. $A$, Schematic of parasagittal D1tdTomato mouse brain slice outlining the recording area within the dorsomedial NAc core. $B, C$, Representative experiments and traces of eEPSCs obtained from D1(+) MSNs (blue circles) and D1( - ) MSNs (open circles). Scale bars: left, $300 \mathrm{pA} / 50 \mathrm{~ms}$; right, $100 \mathrm{pA} / 50 \mathrm{~ms}$. D, Time course of normalized eEPSCs obtained from D1(+) and D1 (-) MSNs in the presence of GABA $A_{B}$ agonist, BAC ( $\left.3 \mu \mathrm{M}\right)$, followed by GABA $R$ antagonist, SCH $50911(5 \mu \mathrm{M})$. BAC decreased eEPSC amplitude that returns to baseline in the presence of SCH 50911. $\boldsymbol{E}$, Average eEPSC amplitude following BAC $(t=20-25)$ and SCH 50911 ( $t=35-40)$. $\boldsymbol{F}$, BAC dose-response curve $(200 \mathrm{~nm}, 600 \mathrm{~nm}, 3$ and $10 \mu \mathrm{m})$ obtained from D1(+) MSNs and D1(-) MSNs showing increased sensitivity to BAC at D1(+) MSNs. Note: $3 \mu \mathrm{m}$ values obtained from averaged eEPSC values in D. G, Rough traces NMDAR-mediated eEPSCs obtained at $+40 \mathrm{mV}$ from D1(+) and D1 (-) MSNs in the continuous presence of NBQX. Scale bars, $100 \mathrm{pA} / 100 \mathrm{~ms}$. $\boldsymbol{H}$, Time course summary and average NMDAR eEPSCs following BAC $(t=15-20 \mathrm{~min}) . I$, Prior application of SCH 50911 alone does not significantly alter eEPSC amplitude and blocks the actions of BAC. Error bars indicate SEM. ${ }^{*} p<0.05$.

$2.53 \pm 0.0332 \mathrm{~Hz}, \mathrm{D} 1(-) \mathrm{BAC}: 1.28 \pm 0.15 \mathrm{~Hz}, n=9, p=$ 0.0014 ; $\mathrm{mEPSC}$ amplitude $=\mathrm{D} 1(+)$ baseline: $-19.61 \pm 0.88 \mathrm{pA}$, $\mathrm{D} 1(+) \mathrm{BAC}:-19.35 \pm 0.82 \mathrm{pA}, n=9, p=0.846$; D1 $(-)$ baseline: $-20.49 \pm 0.61 \mathrm{pA}, \mathrm{D} 1(-) \mathrm{BAC}:-20.13 \pm 0.82 \mathrm{pA}, n=9$, $p=0.666)$. These data rigorously support a presynaptic localization of $\mathrm{GABA}_{\mathrm{B}} \mathrm{R}$ at glutamatergic synapses onto $\mathrm{D} 1(+)$ and $\mathrm{D} 1(-) \mathrm{MSN}$ in the NAc core.

$\mathrm{GABA}_{\mathrm{B}} \mathrm{R}$ activation recruits non-canonical intracellular signaling mechanisms to reduce glutamate release probability at both MSN subtypes

Presynaptic $\mathrm{GABA}_{\mathrm{B}}$ heteroreceptors canonically reduce neurotransmitter release probability by shifting the voltage depen- dence of voltage-gated $\mathrm{Ca}^{2+}$ channels (VGCCs; Kupferschmidt and Lovinger, 2015; Terunuma, 2018). To begin to interrogate this mechanism in the NAc core, we first tested whether prior $\mathrm{GABA}_{\mathrm{B}} \mathrm{R}$ activation diminishes broad-spectrum blockade of VGCCs by cadmium $\left(\mathrm{Cd}^{2+} ; 100 \mu \mathrm{M}\right)$. Prior application of BAC had no effect on the amplitude or kinetics $\left(\mathrm{Cd}^{2+}\right.$-blockade $T_{1 / 2}$; see Materials and Methods) with which $\mathrm{Cd}^{2+}$ blocked evoked glutamatergic transmission (Fig. $3 A-D$; pooled MSNs, BAC: $9.08 \pm 3.15 \%, n=5$; ACSF: $10.11 \pm 1.35 \%, n=5, p=0.509$; $\mathrm{BACCd}^{2+}-T_{1 / 2}: 0.67 \pm 0.15 \mathrm{~min}, n=6$; $\mathrm{ACSF} \mathrm{Cd}^{2+}-T_{1 / 2}: 0.65 \pm$ $0.13 \mathrm{~min}, n=6, p=0.907)$. To specifically rule out subtypeselective actions at VGCCs, we tested whether $\mathrm{GABA}_{\mathrm{B}} \mathrm{R}$ reduces glutamate release probability by inhibiting $\mathrm{N}$ - or $\mathrm{P} / \mathrm{Q}$-type 
A

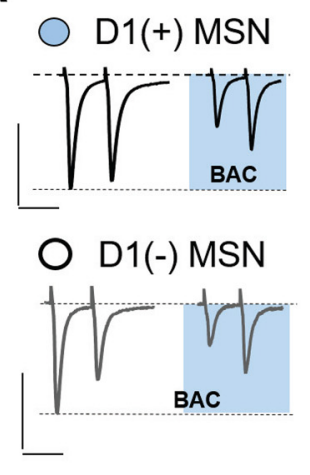

C

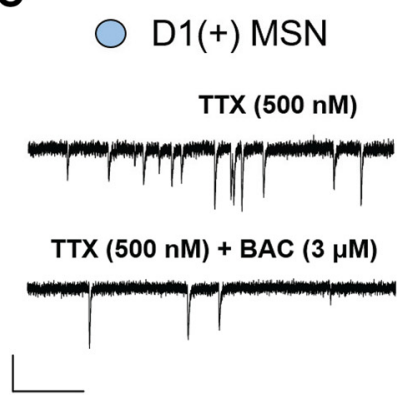

E

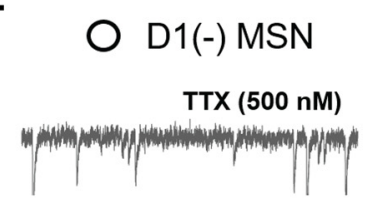

$\operatorname{TTX}(500 \mathrm{nM})+\mathrm{BAC}(3 \mu \mathrm{M})$

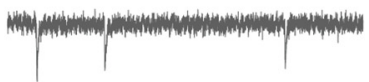

B
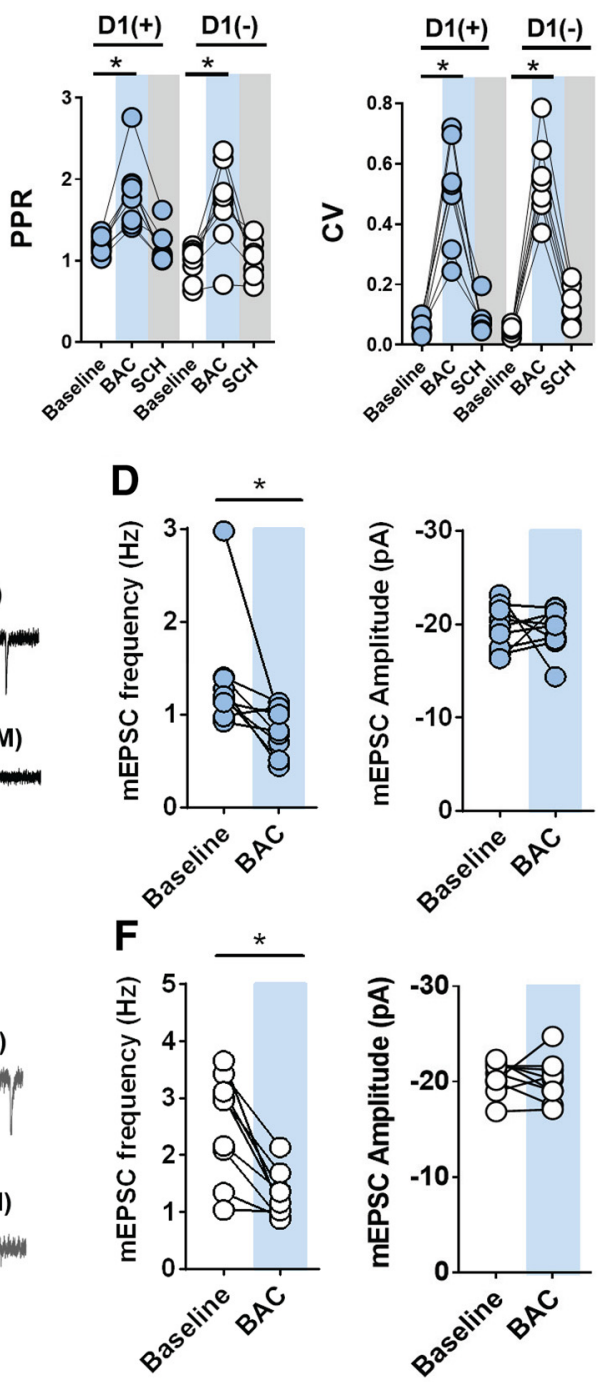

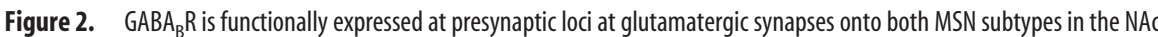
core. $A$, Representative traces of $50 \mathrm{~ms}$ ISI paired pulse eEPSCs obtained from D1(+)MSNs (blue circles) and D1(-) MSNs (open circles) at baseline and in the presence of BAC. Scale bars: top, $200 \mathrm{pA} / 50 \mathrm{~ms}$; bottom, $100 \mathrm{pA} / 50 \mathrm{~ms}$. BAC application increases PPR and $(\boldsymbol{B}) \mathrm{CV}$ at D1 $(+)$ and D1(-) MSNs. $\boldsymbol{C}, \boldsymbol{E}$, Representative traces of TTX-insensitive mEPSCs pre- and post-BAC application at D1(+) MSNs (black) and D1(-) MSNs (gray). Scale bar, 20 pA/1 s. D, F, BAC decreases mEPSC frequency but not amplitude at D1(+) MSNs and D1(-) MSNs. Error bars indicate SEM. ${ }^{*} p<0.05$.

VGCCs. We examined the contribution of N-type VGCCs by superfusing selective N-type VGCC blocker, $\omega$-CTx (800 nм), into the ACSF bath before BAC. $\omega$-CTx significantly reduced eEPSC amplitude at D1 $(+)$ and D1 $(-)$ MSNs but failed to occlude the effects of BAC (Fig. $3 E, J ; \mathrm{D} 1(+): 35.11 \pm 3.35 \%, n=4$, $p=0.9953$; D1 $(-) 34.83 \pm 3.99 \%, n=4, p=0.9999)$. To determine whether $\mathrm{GABA}_{\mathrm{B}} \mathrm{R}$ instead couples selectively to P/Qtype VGCCs, we repeated the above experiment with selective P/Q-type VGCC blocker, $\omega$-AgTx (200 nM). $\omega$-AgTx also resulted in a significant reduction in baseline eEPSC amplitude at $\mathrm{D} 1(+)$ and D1(-) MSN synapses, consistent with previous reports showing that glutamatergic transmission in the NAc is mediated by N- and P/Q-type VGCCs. Prior $\omega$-AgTx application also had no effect on the BAC-induced decrease in eEPSC amplitude at both MSN subtypes (Fig. 3E, J; pooled MSNs: $29.08 \pm$ $3.15 \%, n=3, p=0.593$ ). These findings suggest that $\mathrm{GABA}_{\mathrm{B}} \mathrm{R}$ reduces glutamate release probability independently of $\mathrm{N}$ - and P/Q- type VGCCs. Collectively, these findings suggest that the presynaptic mechanism of $\mathrm{GABA}_{\mathrm{B}} \mathrm{R}$ at glutamatergic synapses in the NAc core is largely VGCC-independent.

We next asked whether $\mathrm{GABA}_{\mathrm{B}} \mathrm{R}$ activity reduces synaptic efficacy by activating G-protein-coupled Kir channels, a downstream effector targeted by several classes of $\mathrm{G}_{\mathrm{i} / \mathrm{o}}$-coupled GPCRs, including $\mathrm{GABA}_{\mathrm{B}} \mathrm{R}$ (Ladera et al., 2008). $\mathrm{BAC}$ application in the presence of $\mathrm{Ba}^{2+}$ (1 $\mathrm{mm}$ ), a nonselective Kir channel blocker, resulted in a decrease in eEPSC amplitude at $\mathrm{D} 1(+)$ and $\mathrm{D} 1(-)$ MSNs that was similar to control conditions (Fig. 3F,J; D1(+): $27.12 \pm 5.67 \%, n=4$, $p=0.4038$; D1 $(-) 31.71 \pm 6.67, n=5$, $p=0.9976)$. Having ruled out mechanisms mediated by classical $\mathrm{G}_{\beta \gamma}$ signaling, we next determined whether $\mathrm{GABA}_{\mathrm{B}} \mathrm{R}$ activation mobilizes $G_{\alpha \text { i }}$ to inhibit adenylyl cyclase (AC) function. Bath-application of AC activator, forskolin $(1 \mu \mathrm{M})$, had no effect on the BAC-induced decrease in eEPSC amplitude at both MSN subtypes (Fig. 3G,J; D1(+): $35.99 \pm 5.11 \%, n=4$, $p=0.9994 ; \mathrm{D} 1(-) 32.72 \pm 3.91 \%, n=4$, $p=0.9999)$. Furthermore, prior application of cell-permeant protein kinase A (PKA) inhibitor, H89 (10 $\mu \mathrm{M})$, did not occlude the effects of BAC at D1 $(+)$ and D1(-) MSN synapses (Fig. 3 H, J; D1(+): $30.65 \pm 3.36 \%, n=5, p<0.001$; D1 $(-)$ : $26.89 \pm 6.04 \%, n=5, p=0.8871)$. These data collectively suggest a mechanism by which $\mathrm{GABA}_{\mathrm{B}} \mathrm{R}$ engages a non-canonical signaling pathway to influence presynaptic function. In line with this hypothesis, disabling $\mathrm{G}_{\mathrm{i} / \mathrm{o}}$-GPCR function with $N$-ethylmaleimide (NEM; $50 \mu \mathrm{M}$ ) diminished but did not block the BAC-induced decrease in eEPSC amplitude (Fig. 4I,J; $\mathrm{D} 1(+): 58.38 \pm 10.27 \%, n=6$, one-way RM ANOVA, BAC effect: $F_{(2,16)}=33.49$, $p<0.001 ; \mathrm{D} 1(+)$ Sidak's post hoc analysis for BAC in ACSF vs BAC in NEM, $p=$ 0.035; D1 $(-): 63.49 \pm 6.54 \%, n=6$, one-way RM ANOVA, BAC effect: $F_{(2,16)}=73.13, p<0.001 ; \mathrm{D} 1(-)$ Sidak's post hoc analysis for BAC in ACSF vs BAC in NEM, $p=0.001)$.

We next examined whether group II mGluRs interact functionally with $\mathrm{GABA}_{\mathrm{B}} \mathrm{R}$ at presynaptic loci to reduce glutamate release probability. Presynaptically-expressed mGluRs in the NAc have previously been shown to decrease vesicular release by selectively targeting P/Q-type VGCCs (Robbe et al., 2002; Mato et al., 2008). Given that $\omega$-AgTx failed to occlude the effects of BAC, we predicted that $G_{A B A} R$ functions through a different pathway than group II mGluRs. Bath-application of selective group II mGluR agonist, LY379268 (200 nM), resulted in a significant reduction in eEPSC amplitude that was accompanied by an increase in PPR and CV, consistent with the presynaptic localization of group II mGluRs in the NAc core (Fig. $4 A, B$; $\mathrm{PPR}=\mathrm{D} 1(+)$ baseline: $1.19 \pm 0.07, \mathrm{D} 1(+) \mathrm{LY}, 1.70 \pm 0.14, n=$ $4, p=0.007$; D1 $(-)$ baseline: $1.08 \pm 0.064$, D1 $(-)$ LY: $1.64 \pm$ 

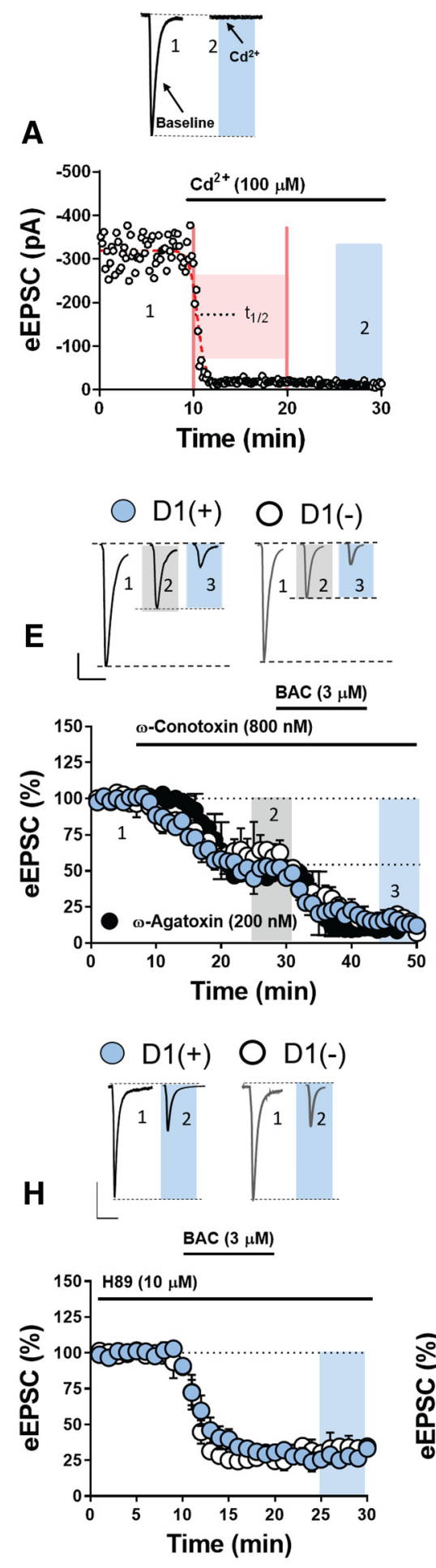

\section{O ACSF \\ $\operatorname{BAC}(3 \mu \mathrm{M})$}

B

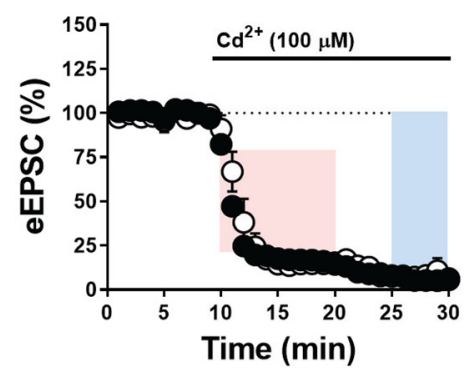

$\mathrm{D} 1(+) \quad \mathrm{OD} 1(-)$
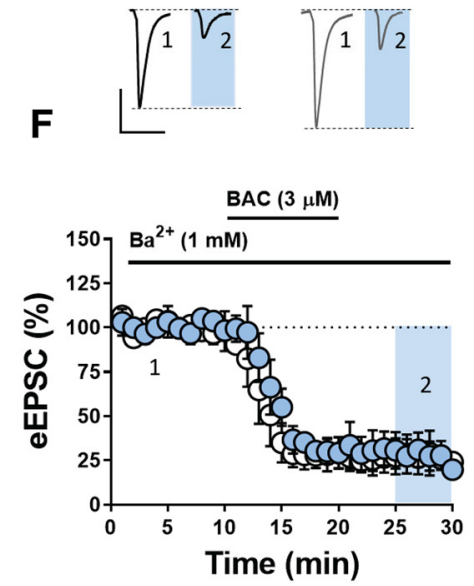
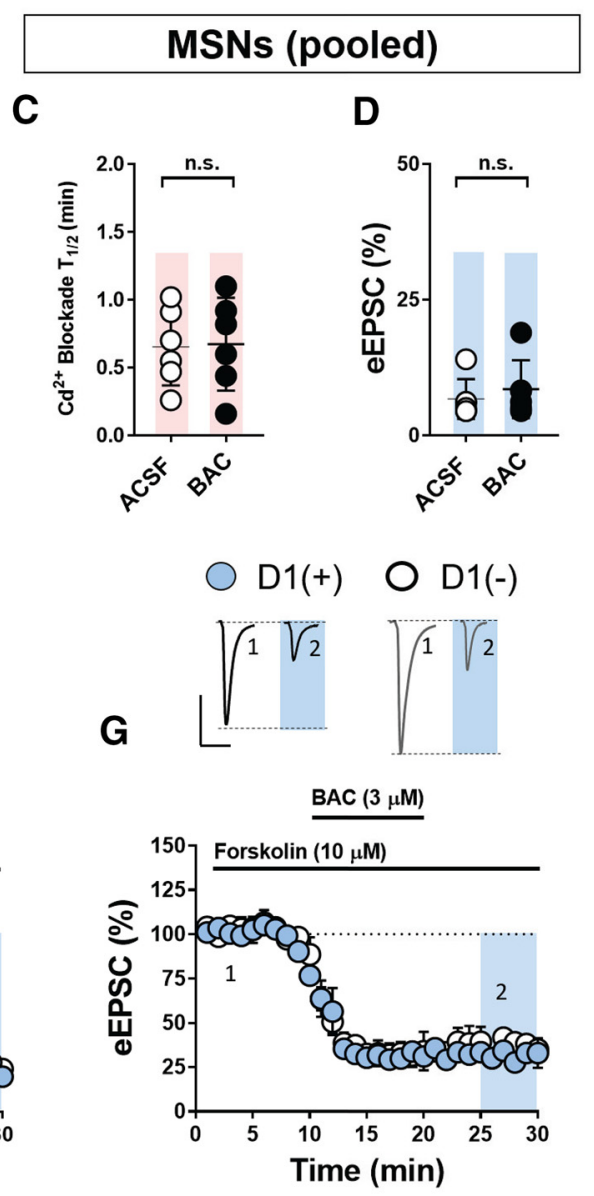

Figure 3. $G A B A_{B} R$ activation recruits a non-canonical intracellular signaling mechanism to reduce glutamate release probability onto MSNs in the NAC core. $A$, Representative experiment and rough traces of the $\mathrm{Cd}^{2+}$-induced blockade of eEPSC from pooled MSNs the time interval from which $T_{1 / 2}$ is obtained. $B$, Time course summary in ACSF and BAC ( $\left.3 \mu \mathrm{M}\right)$-infused ACSF. C, D, Quantified kinetics (pink-shaded region) and magnitude of the $\mathrm{Cd}^{2+}$ block (blue-shaded region). Scale bar (for all traces), $100 \mathrm{pA} / 50 \mathrm{~ms}$. $\boldsymbol{E}$, Time course summary and representative traces showing that $\mathrm{N}$-type VGCC blocker, $\omega$-CTx (800 $\mu \mathrm{M})$, failed to occlude the effects of BAC on eEPSC amplitude at D1 ( + )MSNs (blue circles) and D1 $(-)$ MSNs (open circles; $t=45-50$ min, blue-shaded region, averaged). Black circles indicate time course summary for pooled MSNs of experiments performed with P/Q-type VGCC blocker, $\omega$-AgTx (200 nM), instead of $\omega$-CTx. $\omega$-AgTx also failed to occlude the effects of BAC.F, Time course summary and representative traces showing effect of Kir channel blocker, $\mathrm{Ba}^{2+}(1 \mathrm{~mm})$, on BAC-induced decrease in eEPSC amplitude at D1 $(+)$ and D1 (-) MSNs. G, Time course summary and representative traces showing effect of AC activator, forskolin $(10 \mu \mathrm{M})$, on BAC-induced decrease in eEPSC amplitude at D1 $(+)$ and D1 $(-)$ MSNs. $\boldsymbol{H}$, Time course summary and representative traces showing effect of cell-permeant PKA inhibitor, H89 $(10 \mu \mathrm{m})$, on BAC-induced decrease in eEPSC amplitude at D1 $(+)$ and D1 $(-)$ MSNs. $I$, Time course summary representative traces showing that NEM $(50 \mu \mathrm{m})$ blunted but did not block the effects of BAC on eEPSC amplitude at D1 $(+)$ and D1 $(-)$ MSNs. J, Summary graph of BAC-induced decrease in eEPSC amplitude at D1 (+) and D1(-) MSN synapses following various pharmacological manipulations. Error bars indicate SEM. ${ }^{*} p<0.05$, n.S., not significant. 


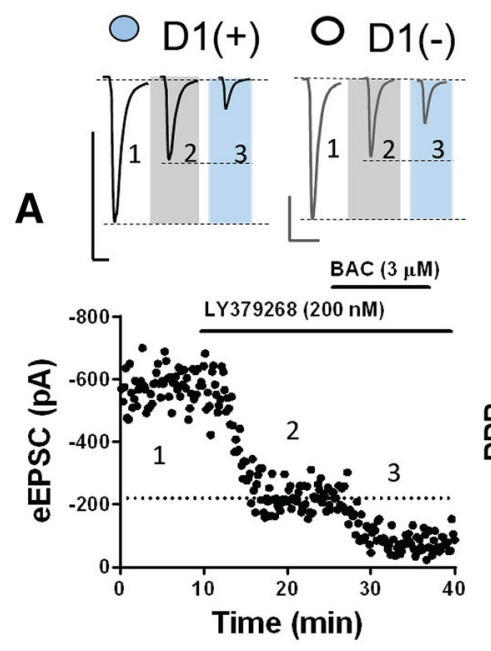

D
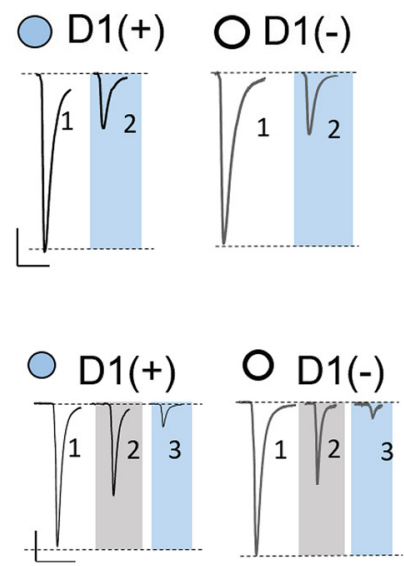
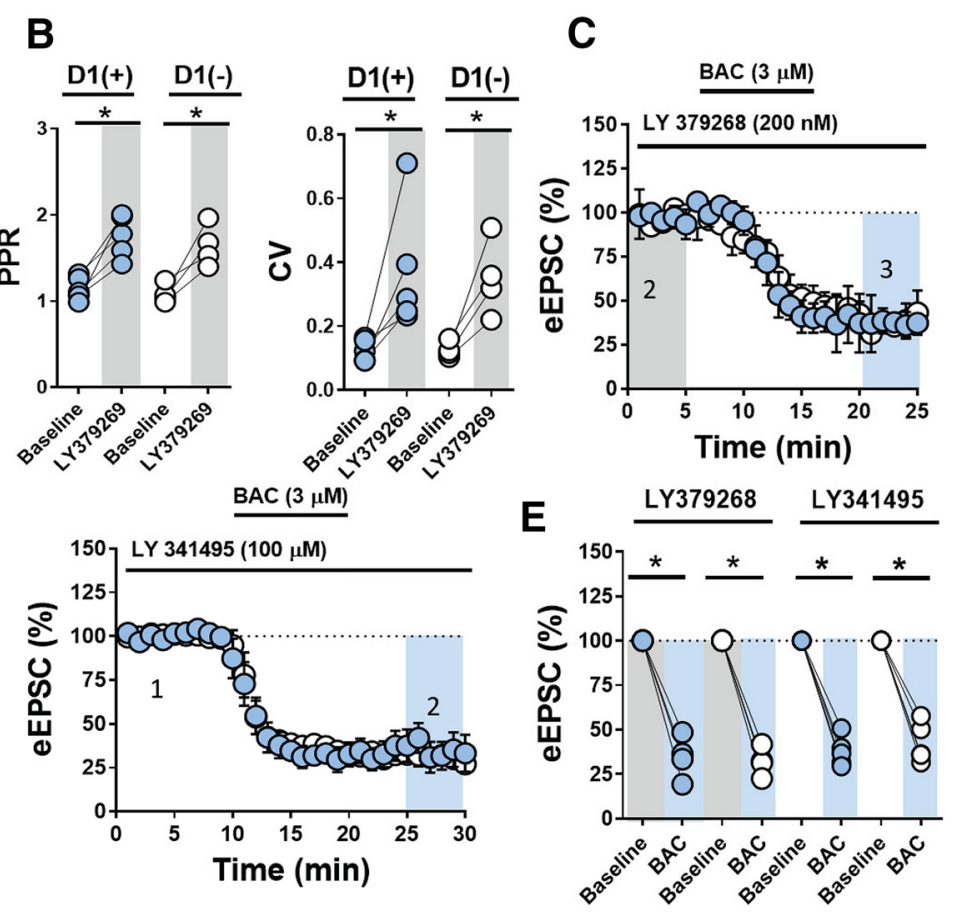
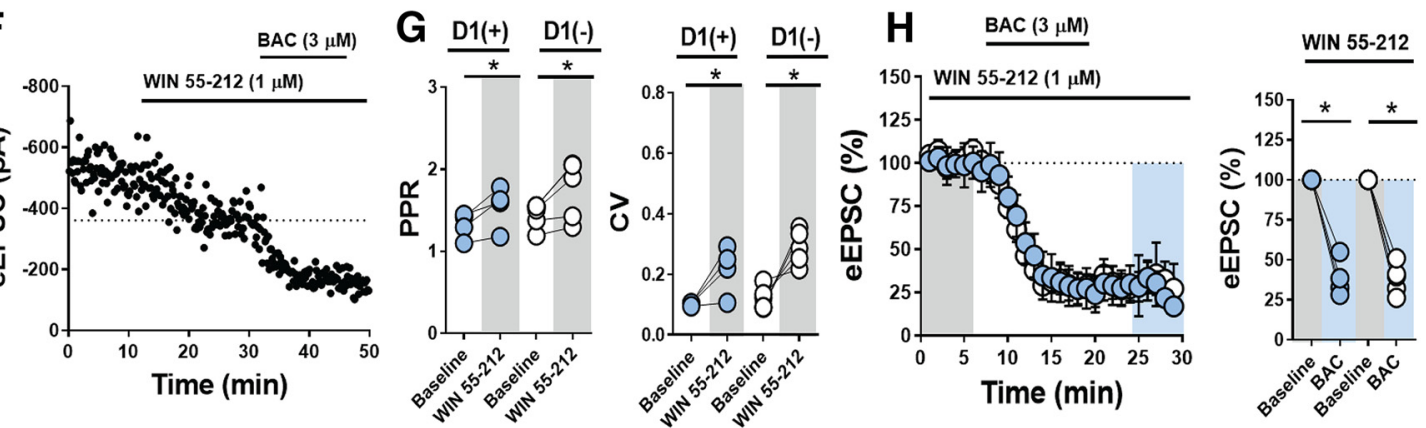

\section{D1(+)}

I

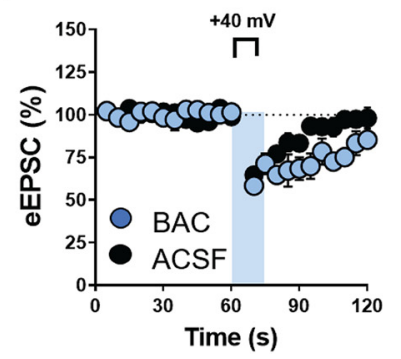

J

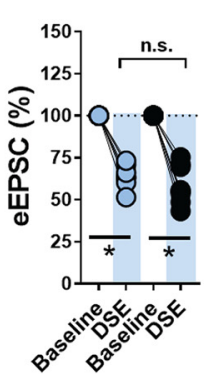

CB1 receptor

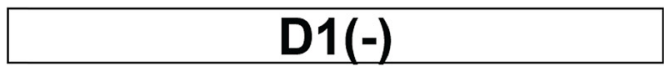

K

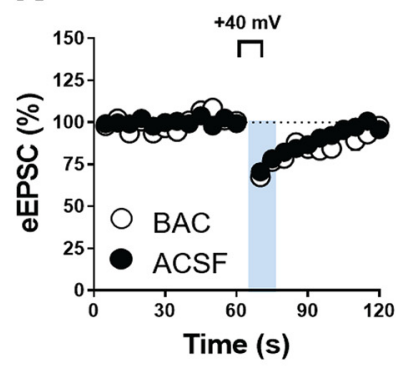

L

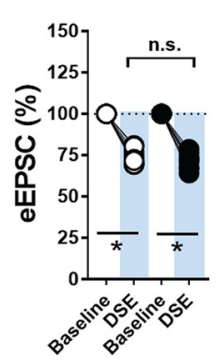

Figure 4. $G A B A_{B} R$ is functionally distinct from $m G l u R s$ and $C B_{1} R$ at glutamatergic synapses in the NAc core. $A$, Representative experiment and traces showing that group II $m G l u R$ agonist, LY379268 (200 nM), fails to occlude the effects of BAC on eEPSC amplitude at D1 (+) and D1 (-) MSNs. Scale bar (for all traces), 100 pA/50 ms. B, LY379268 application increases PPR and CV at D1 (+) and D1(-) MSNs, consistent with a presynaptic locus of expression. $C$, Time course summary showing the effects of BAC on eEPSC amplitude renormalized to stabilized baseline in the presence of LY379268 (gray). D, Representative traces and time course summary showing that prior application of pan-mGluR antagonist, LY341495, does not prevent (Figure legend continues.) 
0.14, $n=5, p=0.0246 ; C V=\mathrm{D} 1(+)$ baseline: $0.03 \pm 0.01$, D1(+) LY: $0.41 \pm 0.09, n=5, p=0.0198$; D1 $(-)$ baseline: $0.12 \pm 0.01$, D1 $(-)$ LY: $0.35 \pm 0.07, n=4, p=0.0141)$. Subsequent application of BAC decreased eEPSC amplitude at D1 $(+)$ and D1 $(-)$ MSNs that was also indistinct from control conditions, suggesting that presynaptic group II mGluRs and $\mathrm{GABA}_{\mathrm{B}} \mathrm{R}$ recruit distinct intracellular effectors to reduce glutamatergic transmission in the NAc core (Fig. $4 C, E ; \mathrm{D} 1(+)$ ): $34.45 \pm 6.91 \%$, $n=4, p=0.6412$; D1 $(-): 32.02 \pm 4.53 \%, n=4, p=0.1032)$. In the cerebellum, $\mathrm{GABA}_{\mathrm{B}} \mathrm{R}$ couples to presynaptic metabotropic glutamate receptors $\left(\mathrm{mGluR}_{1}\right)$ such that $\mathrm{GABA}_{\mathrm{B}} \mathrm{R}$ activation augments mGluR sensitivity to synaptic glutamate levels (Tabata and Kano, 2006, 2010). To determine whether a similar relationship exists in the NAc, LY3431495 was superfused at a concentration that antagonizes all mGluRs $(100 \mu \mathrm{M})$. In the presence of LY3431495, BAC application resulted in a similar reduction in eEPSC amplitude at D1 $(+)$ and D1(-) MSNs relative to control conditions (Fig. $4 D, E$; D1 $(+): 39.74 \pm 4.2 \%, n=5, p=0.999$; $\mathrm{D} 1(-) 43.07 \pm 5.55 \%, n=5, p=0.4951)$. These data strongly suggest that $\mathrm{GABA}_{\mathrm{B}} \mathrm{R}$ functions independently of mGluRs in the NAc core.

We next examined whether $\mathrm{GABA}_{\mathrm{B}} \mathrm{R}$ shares a common intracellular mechanism with $\mathrm{CB}_{1} \mathrm{R}$, the cognate receptor for endogenous cannabinoids (eCBs), such as 2-arachidonylglycerol (2-AG) and anandamide. We selected $\mathrm{CB}_{1} \mathrm{R}$ because it is the most ubiquitously expressed $\mathrm{G}_{\mathrm{i} / \mathrm{o}}$-GPCR in the mammalian CNS, generally restricted to presynaptic domains, and critically regulates excitatory transmission in the striatum (Robbe et al., 2003; Grueter et al., 2010; Castillo et al., 2012). To ascertain the functional difference between $C_{1} R$ and $G_{A B A} R$, we first looked at whether $\mathrm{CB}_{1 / 2} \mathrm{R}$ agonist, WIN 55-212 $(1 \mu \mathrm{M})$, occludes the effects of BAC on eEPSC amplitude. WIN 55-212 resulted in a significant decrease in eEPSC amplitude that was accompanied by an increase in PPR and CV (Fig. 4F, G; PPR $=\mathrm{D} 1(+)$ baseline: $1.31 \pm 0.09, \mathrm{D} 1(+) \mathrm{WIN}: 1.55 \pm 0.15, n=4, p=0.0439)$; D1 $(-)$ baseline: $1.44 \pm 0.80, \mathrm{D} 1(-) \mathrm{WIN}: 1.75 \pm 0.18, n=5, p=$ 0.0336); $\mathrm{CV}=\mathrm{D} 1(+)$ baseline: $0.010 \pm 0.003, \mathrm{D} 1(+) \mathrm{WIN}$ $0.22 \pm 0.05, n=4, p=0.02771$; D1 $(-)$ baseline: $0.12 \pm 0.018$, D1 $(-)$ WIN: $0.29 \pm 0.28, n=5, p=0.0079)$. However, WIN 55-212 failed to occlude BAC at synapses onto both MSN subtypes, suggesting that presynaptically-expressed $\mathrm{CB}_{1} \mathrm{R}$ and $\mathrm{GABA}_{\mathrm{B}} \mathrm{R}$ also modulate presynaptic release probability via distinct intracellular mechanisms (Fig. $4 H$; D1(+): $35.60 \pm 6.78 \%$, $n=4, p=0.6412 ; \mathrm{D} 1(-) 38.07 \pm 4.71 \%, n=5, p=0.1032)$. We next tested the effects of BAC on DSE, a $\mathrm{CB}_{1} \mathrm{R}$-dependent form of short-term plasticity that transiently decreases glutamate release probability. N- and P/Q-type VGCCs have been implicated in the expression of $\mathrm{CB}_{1} \mathrm{R}$-induced DSE in various regions, providing

\section{$\leftarrow$}

(Figure legend continued.) the BAC-induced decrease in eEPSC amplitude. $\boldsymbol{E}$, Summary graph quantifying the effects of mGluR-specific pharmacological manipulations on $G A B A_{B} R$ function (averaged at $t=35-40 \mathrm{~min}$; blue). $\boldsymbol{F}$, Representative experiment and traces showing that $\mathrm{CB}_{1 / 2} \mathrm{R}$ agonist, WIN 55-212 (1 $\left.\mu \mathrm{m}\right)$, depresses eEPSC amplitude at D1(+) and D1 (-) MSNs but fails to occlude the effects of BAC. Scale bar (for all traces), $50 \mathrm{pA} / 50$ ms. G, Bath application of WIN 55-212 increased PPR and CV at glutamatergic synapses onto D1 (+) and D1 (-) MSNs, confirming the canonical presynaptic expression of $C B_{1} R$ in the NAc. $\boldsymbol{H}$, Time course summary and quantification showing the effects of BAC on eEPSC amplitude renormalized to stabilized baseline in the presence of WIN 55-212 (gray). $\boldsymbol{I}-\boldsymbol{L}$, Time course summaries and quantification (obtained at $t=60 \mathrm{~s}$ ) of DSE followed by DSE in the presence of BAC for D1 $(+)$ and D1 $(-)$ MSNs. All DSE experiments performed in pairs such that DSE was repeated within-cell in the presence of BAC. Error bars indicate SEM. ${ }^{*} p<0.05$, n.s., not significant. us with an additional means to assess the contribution of VGCCs in the mechanism of $\mathrm{GABA}_{\mathrm{B}} \mathrm{R}$ (Kreitzer and Regehr, 2001; Heifets et al., 2008; Castillo et al., 2012). Postsynaptic depolarization from -70 to $+40 \mathrm{mV}$ for $10 \mathrm{~s}$ resulted in a significant reduction in eEPSC amplitude at D1(+) and D1(-) MSN synapses, confirming the presence of DSE (Fig. $4 I-L ; D 1(+)$ DSE-ACSF: $64.97 \pm 2.69 \%, n=8, p<0.0001$; D1 $(-)$ DSE-ACSF: $74.13 \pm$ $1.61 \%, n=9, p<0.0001)$. Following a triplicate DSE baseline, BAC was superfused into the ACSF bath, resulting in a significant decrease in eEPSC amplitude that stabilized at the 20 min time point. Subsequent trials of DSE were then performed in the presence of BAC. DSE remained completely intact following BAC application at $\mathrm{D} 1(+)$ and $\mathrm{D} 1(-) \mathrm{MSN}$ synapses, indicating that BAC did not occlude the expression of DSE (Fig. $4 I-L$; D1 $(+$ ) DSE-BAC: $59.1 \pm 4.38, n=8, p=0.2321$; D1 $(-)$ DSE-BAC: $71.56 \pm 1.69, n=, p=0.1779)$.

\section{Elevating presynaptic $\mathrm{Ca}^{2+}$ influx abrogates downstream $\mathrm{GABA}_{\mathrm{B}} \mathrm{R}$ effector function}

The above data suggest that presynaptic $G_{A B A} R$ function at glutamatergic synapses in the NAc core is distinct from the actions of $\mathrm{GABA}_{\mathrm{B}} \mathrm{R}$ elsewhere in the CNS. One possibility is that $\mathrm{GABA}_{\mathrm{B}} \mathrm{R}$ activation interferes with vesicular release machinery. To gain insight into how $\mathrm{GABA}_{\mathrm{B}} \mathrm{R}$ may be involved in vesicular release, we asked whether increasing presynaptic $\mathrm{Ca}^{2+}$ influx during the electrically-evoked fiber volley modulates the effects of BAC. We accomplished this by bath-applying $\mathrm{K}^{+}$channel blocker, 4-aminopyridine (4-AP; $100 \mu \mathrm{M})$, at a concentration selective for voltage-gated $\mathrm{K}^{+}$channels $\left(\mathrm{K}_{\mathrm{V}}\right.$; Fig. $5 A$ ). Selective blockade of $\mathrm{K}_{\mathrm{V}}$ channels elongates action potential half-width, increasing VGCC open probability and presynaptic $\mathrm{Ca}^{2+}$ conductance (Solís and Nicoll, 1992; Iremonger and Bains, 2009). Application of 4-AP alone significantly increased eEPSC amplitude at $\mathrm{D} 1(+)$ and $\mathrm{D} 1(-) \mathrm{MSNs}$ (Fig. $5 \mathrm{~B}, \mathrm{C}$; D1(+) 4-AP: $142.26 \pm 12.38, n=6, p<0.001$; D1 $(-)$ 4-AP: $143.55 \pm 11.34$, $n=6, p<0.001)$ and was accompanied by a reduction in PPR, consistent with a $\mathrm{Ca}^{2+}$-dependent enhancement of presynaptic release probability (Fig. $5 D$; PPR $=\mathrm{D} 1(+)$ baseline: $1.26 \pm 0.13$, $\mathrm{D} 1(+)$ 4-AP: $0.52 \pm 0.28, n=5, p=0.0468$; D1 $(-)$ baseline: $1.16 \pm 0.09, \mathrm{D} 1(-)$ 4-AP: $0.76 \pm 0.13, n=4, p=0.0169)$. Subsequent application of BAC in the presence of 4-AP resulted in a depression in eEPSC amplitude at D1 $(+)$ and D1(-) MSNs that was significantly attenuated relative to control conditions (Fig. 5A-C; D1(+): $66.71 \pm 3.09 \%, n=5, p=0.0001$; D1(-): $69.35 \pm 7.02 \%, n=4, p=0.0003)$. 4-AP also negated BACinduced changes in PPR and fully reversed the depression in eEPSC amplitude elicited by BAC (Fig. 5D-F; PPR $=\mathrm{D} 1(+)$ 4 -AP + BAC: $0.79 \pm 0.12, n=5, p=0.214$; D1 $(-) 4-\mathrm{AP} \pm \mathrm{BAC}$ : $0.73 \pm 0.11, n=4, p=0.4374 ; \mathrm{D} 1(+) 4$-AP reversal: $116.40 \pm$ $7.89 \%, n=5, p=0.0033 ; \mathrm{D} 1(-)$ 4-AP reversal: $107.08 \pm$ $10.85 \%, n=4, p=0.0093)$. To verify that 4 -AP increased $\mathrm{Ca}^{2+}$ influx secondary to its action at $\mathrm{K}_{\mathrm{V}}$ channels, we repeated this experiment in low- $\mathrm{Ca}^{2+} \mathrm{ACSF}\left(1 \mathrm{mM} \mathrm{Ca}{ }^{2+} / 3 \mathrm{mM} \mathrm{Mg}^{2+}\right)$. Prior application of 4-AP in low- $\mathrm{Ca}^{2+} \mathrm{ACSF}$ returned the BACinduced decrease in eEPSC amplitude back to baseline conditions at MSN [pooled $\mathrm{D} 1(+)$ and $\mathrm{D} 1(-)$ ] synapses, suggesting that increased $\mathrm{Ca}^{2+}$ influx via $\mathrm{K}_{\mathrm{V}}$ channel blockade can successfully overcome the inhibitory actions of BAC at glutamatergic synapses in the NAc core (Fig. 5C; pooled MSNs: $40.58 \pm 9.28 \%, n=$ $11, p=0.3533)$. 
A

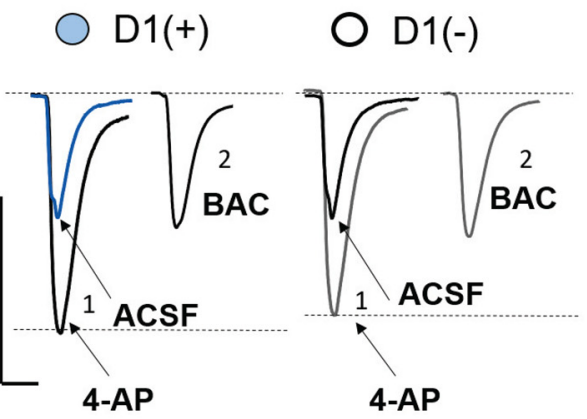

B

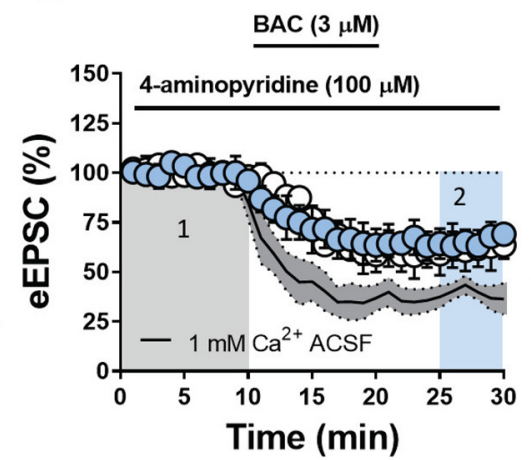

C

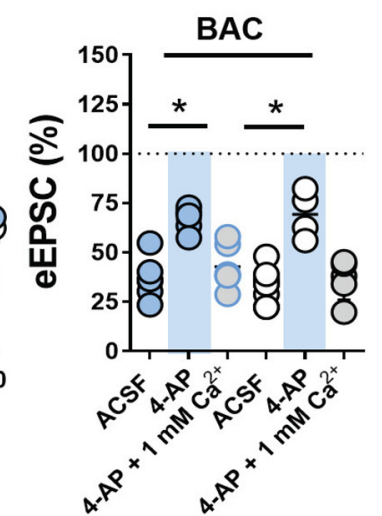

D

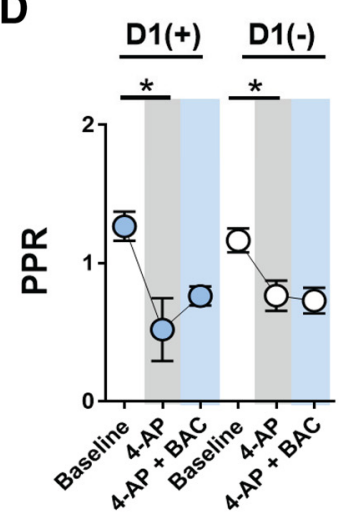

E

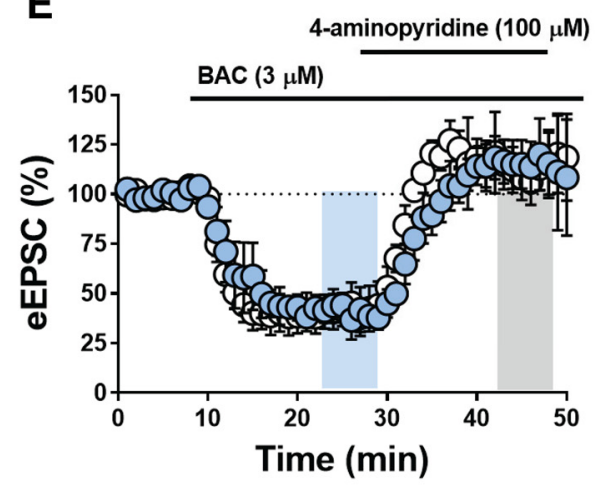

$\mathbf{F}$

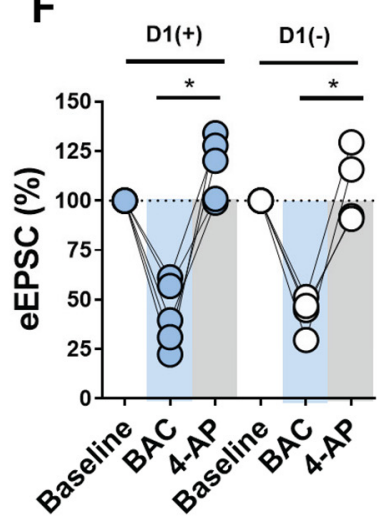

Figure 5. Elevating presynaptic $\mathrm{Ca}^{2+}$ influx abrogates downstream $\mathrm{GABA}_{\mathrm{B}} \mathrm{R}$ effector function. $\boldsymbol{A}, 1$ : Representative traces showing that 4-AP application increases eEPSC amplitude and decay time at glutamatergic synapses onto D1 (+) and D1(-) MSNs. 2: eEPSC amplitude at D1 + ) and D1(-) MSN synapses in the presence of BAC. Scale bar: $200 \mathrm{pA} / 20 \mathrm{~ms}$. B, Prior bath application of 4-AP blunts the BAC-induced decrease in eEPSC amplitude at D1(+) and D1(-) MSNs). Low $\mathrm{Ca}^{2+}(1 \mathrm{~mm})$ ACSF returns BAC-induced decrease in eEPSC amplitude to control conditions (pooled D1 (+) and D1(-) MSNs, line with shaded gray area within SEM). C, Graph of average eEPSC amplitude in the presence of BAC with 4-AP, 4-AP + low Ca ${ }^{2+}$ ACSF, and ACSF-only control conditions $(t=25-30 \mathrm{~min}) . \boldsymbol{D}, 4-\mathrm{AP}$ application alone decreases PPR and negates the increase in PPR elicited by BAC. $E$, Time course summary showing that 4-AP application reverses eEPSC amplitude in the presence of BAC at D1 $(+)$ and D1 (-) MSNs. $F$, Graph of average eEPSC amplitude following 4-AP reversal in the presence of BAC (blue, $t=20-25 \mathrm{~min}$ ) and 4-AP + BAC (gray, $t=45-50)$ for D1(+) and D1(-) MSNs. Error bars indicate SEM. ${ }^{*} p<0.05$.

Genetically disrupting the G $\beta \gamma$-SNAP-25 interaction blunts the synaptic effect of $\mathrm{GABA}_{\mathrm{B}} \mathrm{R}$ on glutamatergic transmission in the NAc core

$\mathrm{G}_{\mathrm{i} / \mathrm{o}}$-coupled GPCR-induced mobilization of G $\beta \gamma$ at the presynaptic active zone has been shown to interfere with exocytotic fusion mediated by ternary SNARE complexes. G $\beta \gamma$-dependent targeting of membrane-associated target SNARE proteins ( $\mathrm{t}$ SNAREs), such as SNAP-25, has been shown to prevent the association of synaptotagmin with the SNARE complex to reduce vesicular release probability (Wells et al., 2012; Zurawski et al., 2019). The G $\beta \gamma$-SNARE interaction is $\mathrm{Ca}^{2+}$-sensitive, as pharmacological enhancement of presynaptic $\left[\mathrm{Ca}^{2+}\right]$ can offset $\mathrm{G} \beta \gamma$ binding to restore baseline synaptic transmission (Gerachshenko et al., 2005). Given that $\mathrm{GABA}_{\mathrm{B}} \mathrm{R}$ heteroreceptor function in the NAc core is (1) putatively VGCC, Kir, AC, PKA, and mGluRindependent and (2) blunted by 4-AP-induced increases in presynaptic $\mathrm{Ca}^{2+}$ influx, we hypothesized that $\mathrm{GABA}_{\mathrm{B}} \mathrm{R}$ engages a presynaptic G $\beta \gamma$-SNARE mechanism at glutamatergic synapses onto MSNs. To test this hypothesis, we used transgenic mice lacking the C-terminally-located $\mathrm{G} \beta \gamma$-binding motif of SNAP- 25 (Fig. 6A). Inserting the SNAP25 33 allele into the WT SNAP-25 locus attenuates G $\beta \gamma$-SNAP- 25 complex formation by $\sim 47 \%$ without significantly disrupting evoked synaptic transmission (Zurawski et al., 2019).
We prepared acute ex vivo brain slices from SNAP25 3 and WT mice and recorded eEPSCs in unlabeled MSNs. Interestingly, baseline PPR of glutamatergic transmission in SNAP25 3 mice was significantly elevated relative to WT controls, consistent with a SNAP-25-specific reduction in vesicular exocytosis [Fig. 6B; MSNs (unlabeled), $3 \mu \mathrm{M}$, WT baseline $50 \mathrm{~ms}$ ISI, PPR: $0.99 \pm$ $0.14, n=7$; SNAP25 $\Delta 3: 1.56 \pm 0.09, n=5, p=0.0021]$. Bathapplication of BAC $(3 \mu \mathrm{M})$ in slices obtained from littermate (WT) control mice decreased eEPSC amplitude comparably to D1tdTomato mice. However, BAC application $(3 \mu \mathrm{M})$ in SNAP25 23 mice resulted in a significantly blunted decrease in eEPSC amplitude [Fig. 6C; MSNs (unlabeled), WT: $27.54 \pm$ $1.14 \%, n=10$; SNAP25 3 : $55.45 \pm 4.94 \%, n=5, p=0.0003$ ] To discern the functional relationship between $\mathrm{GABA}_{\mathrm{B}} \mathrm{R}$ and SNAP25 more clearly, we superfused BAC at lower concentrations to elicit submaximal $\mathrm{GABA}_{\mathrm{B}} \mathrm{R}$ activity. Although the BACinduced decrease in eEPSC amplitude was modestly reduced at higher BAC concentrations ( $3 \mu \mathrm{M}, 10 \mu \mathrm{M})$, the effect was significantly attenuated at lower concentrations $(200 \mathrm{nM}, 600 \mathrm{nM})$ in SNAP25 3 mice (Fig. $6 E, G$; 200 nM, WT: $79.35 \pm 2.09, n=6$; SNAP25 $\Delta 3$ : $92.64 \pm 7.92, n=4, p=0.0083 ; 600 \mathrm{~nm}$, WT: $62.71 \pm 4.10, n=7$; SNAP25 $\Delta 3: 83.03 \pm 4.12 \%, n=5, p=$ 0.0074). Furthermore, BAC application in WT mice was accompanied by a time-locked increase in PPR at all concentrations 
A

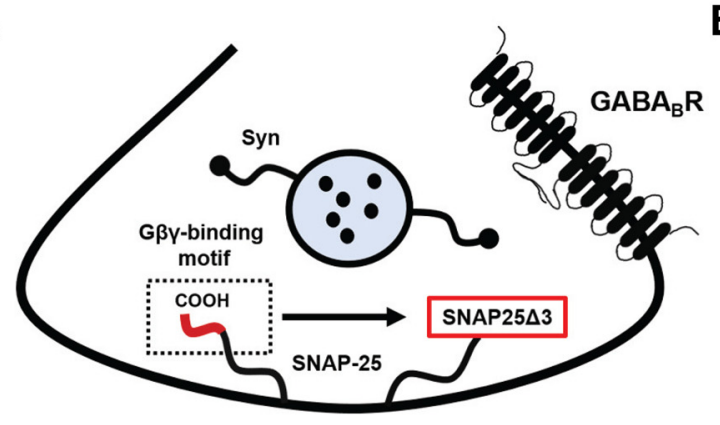

C

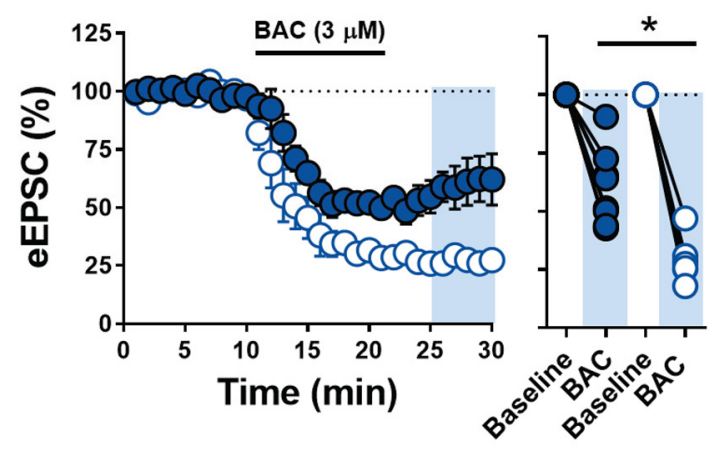

E

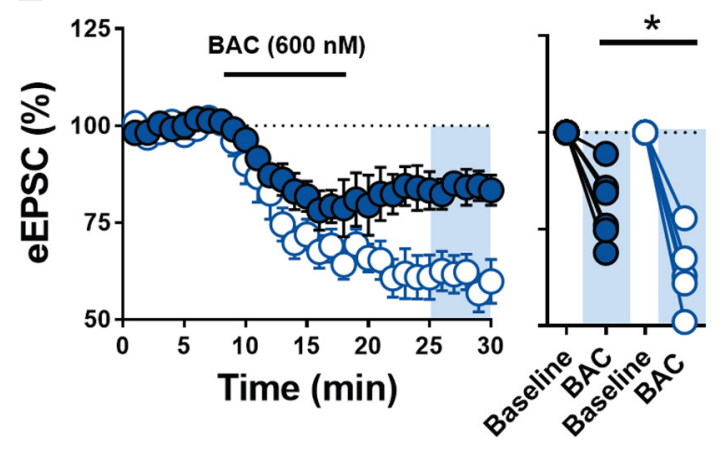

G

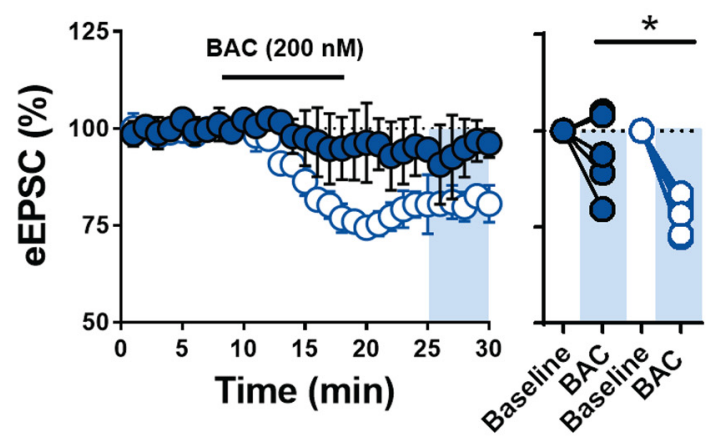

B

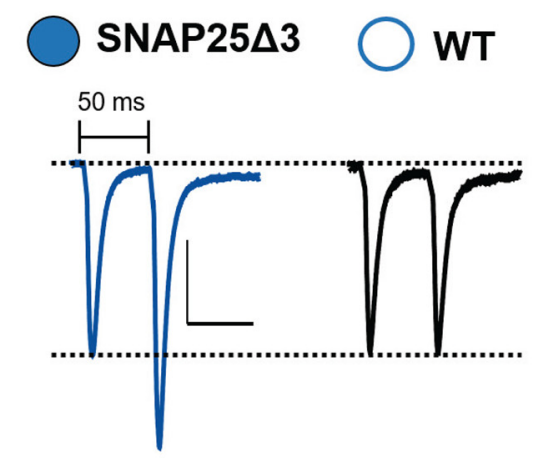

D
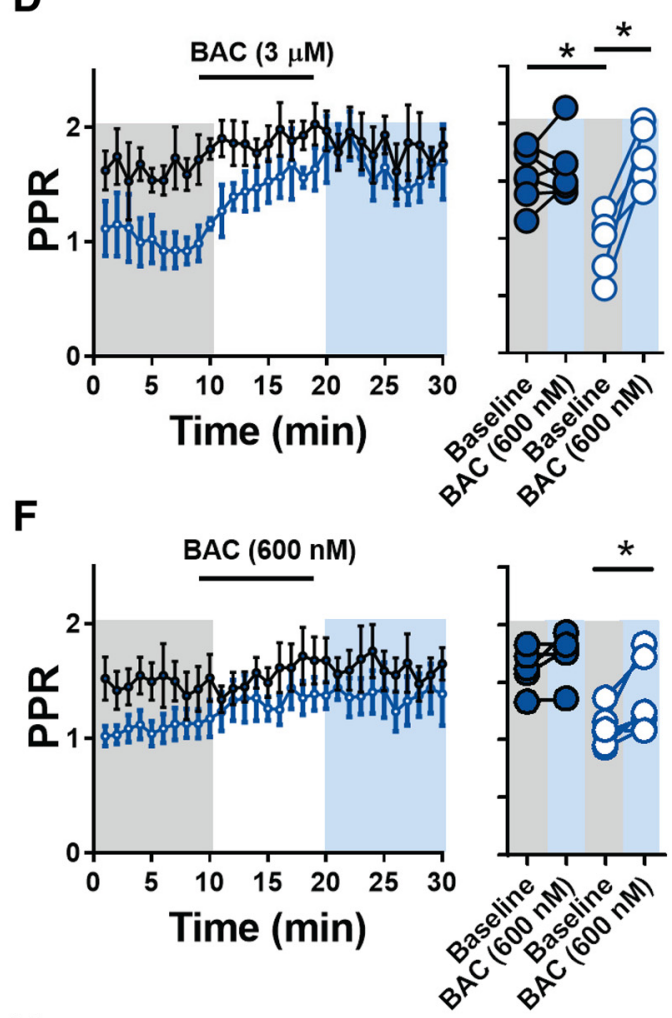

H

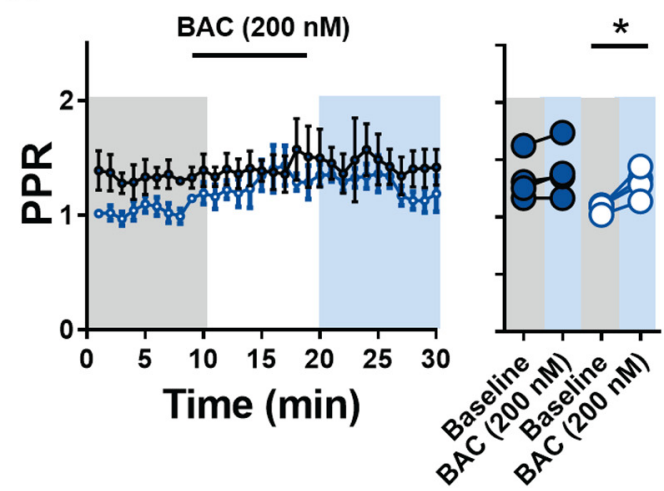

Figure 6. Genetically reducing the $\mathrm{G}_{\beta \gamma}-\mathrm{SNAP}-25$ interaction blunts the synaptic effect of $\mathrm{GABA}_{B} \mathrm{R}$ at glutamatergic synapses in the NAc core. $A$, Schematic of presynaptic terminal with C-terminally truncated SNAP-25 in transgenic SNAP25 3 mouse. Syn indicates SNAP-25 binding partner, synaptotagmin-1. B, Representative traces of averaged 50 ms paired-pulse eEPSCs in SNAP25 33 (left, blue circle) and WT mice (right, open circle). Basal PPR at $50 \mathrm{~ms}$ is significantly increased in SNAP25 33 mice relative to WT littermate controls. Scale bars, $100 \mathrm{pA} / 50 \mathrm{~ms}$. C, Time course summary of eEPSC amplitude obtained from unlabeled MSNs in SNAP25 3 mutant mice (blue circles) and WT littermate control mice (open circles) in the presence $3 \mu \mathrm{M}$ BAC. D, PPR time course summary and averages pre-BAC (gray area) and post-BAC (blue area) at $3 \mu \mathrm{m}$. $\boldsymbol{E}$, Time course summary of eEPSC amplitude obtained from unlabeled MSNs in SNAP25 3 mutant mice (blue circles) and WT littermate control mice (open circles) in the presence $600 \mathrm{~nm} \mathrm{BAC.F,} \mathrm{PPR} \mathrm{time} \mathrm{course} \mathrm{summary} \mathrm{and} \mathrm{averages} \mathrm{pre-BAC} \mathrm{(gray} \mathrm{area)} \mathrm{and} \mathrm{post-BAC} \mathrm{(blue} \mathrm{area)} \mathrm{at} 600 \mathrm{~nm}$. G, Time course summary of eEPSC amplitude obtained from unlabeled MSNs in SNAP25 3 mutant mice (blue circles) and WT littermate control mice (open circles) in the presence $200 \mathrm{~nm}$ BAC. $\boldsymbol{H}$, PPR time course summary and averages pre-BAC (gray area) and post-BAC (blue area) at $200 \mathrm{~nm}$. Error bars indicate SEM. ${ }^{*} p<0.05$. 

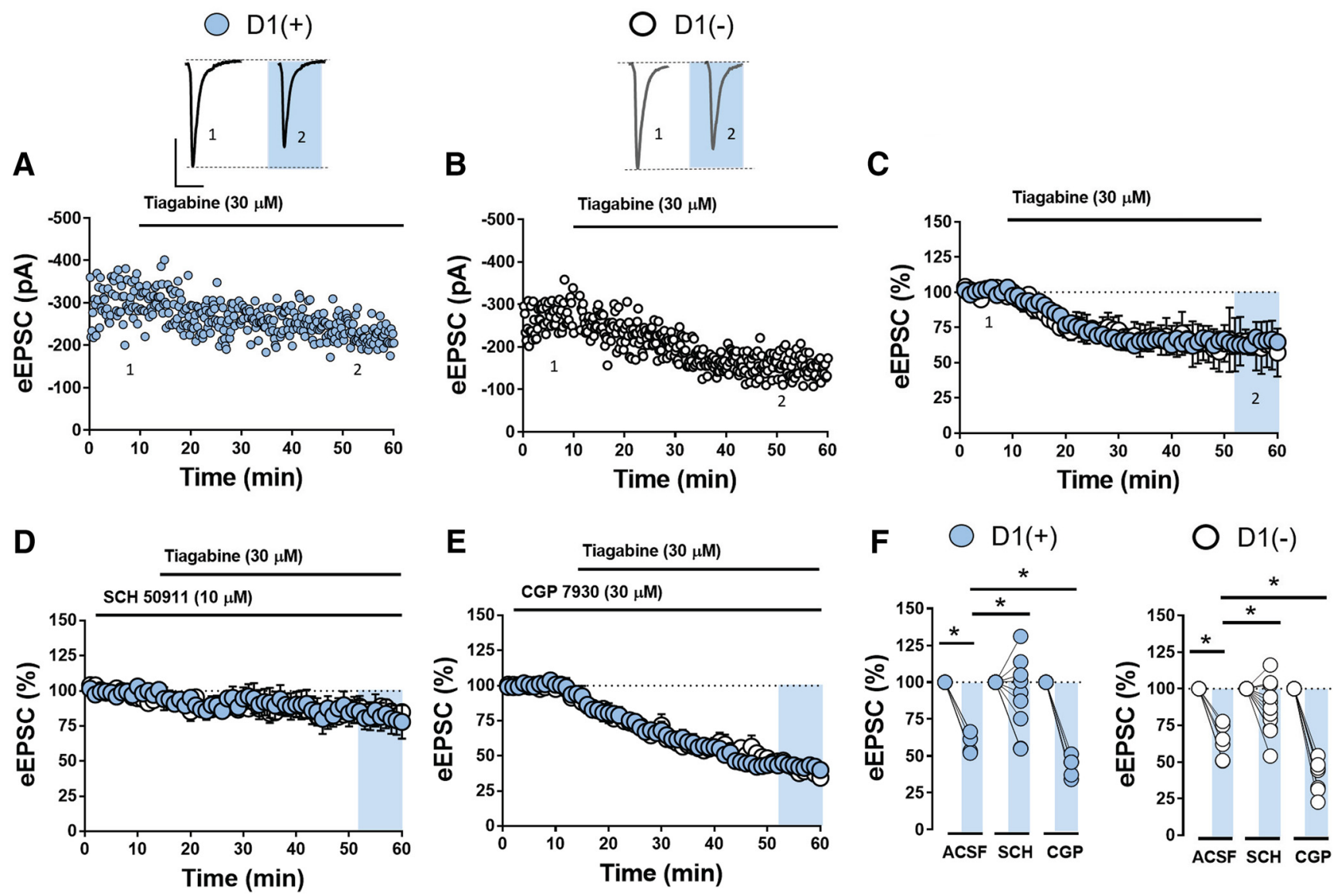

Figure 7. GAT-1-regulated ambient GABA acts on $\mathrm{GABA}_{B} \mathrm{R}$ to decrease glutamatergic transmission in the NAc core. $A, B$, Representative experiment and traces of eEPSCs obtained from D1 (+) MSNs (blue circles) and D1(-) MSNs (open circles) in the NAc core. Scale bar, $200 \mathrm{pA} / 50 \mathrm{~ms}$. C, Time course of normalized eEPSC amplitude from D1(+) and D1(-) MSNs in the presence of GABA reuptake (GAT-1) inhibitor, tiagabine (30 $\mu \mathrm{M})$. D, Time course of normalized eEPSC amplitude from D1(+)and D1(-) MSNs in the presence of tiagabine + SCH $50911(5 \mu \mathrm{M})$. $\boldsymbol{E}$, Time course of normalized eEPSC amplitude from D1 $(+)$ and D1 $(-)$ MSNs in the presence of tiagabine $(30 \mu \mathrm{m})$ and GABA R-PAM, CGP $7930(30 \mu \mathrm{M}) . F$, Quantification of average eEPSC amplitude $(t=55-60$ $\mathrm{min}$ ) of tiagabine in normal ACSF, CGP 7930, and SCH 50911 at D1 (+) and D1 (-) MSNs. Error bars indicate SEM. ${ }^{*} p<0.05$.

tested, whereas BAC application in SNAP25 $\Delta 3$ mice did not significantly alter PPR (Fig. $6 D, F, H ; 200 \mathrm{nM}$, WT baseline: $1.12 \pm$ 0.05 , BAC: $1.34 \pm 0.08, n=4, p=0.0208$; SNAP25 $\Delta 3$ baseline: $1.35 \pm 0.11$, BAC: $1.44 \pm 0.19, n=4, p=0.0964 ; 600 \mathrm{nM}, \mathrm{WT}$ baseline: $1.16 \pm 0.11$, BAC: $1.36 \pm 0.15, n=6, p=0.0306$; SNAP25 $\Delta 3$ baseline: $1.46 \pm 0.17$, BAC: $1.61 \pm 0.16, n=5, p=$ $0.1419 ; 3 \mu \mathrm{M}$, WT baseline: $1.04 \pm 0.19$, BAC: $1.73 \pm 0.13, n=4$, $p=0.0054$; SNAP25 3 baseline: $1.76 \pm 0.16$, BAC: $1.79 \pm 0.14$, $n=8, p=0.6367)$. These findings indicate that presynaptic $\mathrm{GABA}_{\mathrm{B}} \mathrm{R}$ function at glutamatergic synapses in the NAc core is impaired in mice lacking the $\mathrm{G}_{\beta \gamma}$-targeting motif of SNAP-25.

GAT-1-regulated ambient GABA acts on $G A B A_{B} R$ to decrease glutamatergic transmission in the NAc core

$\mathrm{GABA}_{\mathrm{B}} \mathrm{R}$ expressed on glutamate terminals may serve as a heteroreceptor for GABA released from contiguous GABAergic synapses in the NAc. To assess whether circuit-wide elevations in ambient GABA modulate glutamatergic synapses in the NAc core, we bath-applied tiagabine $(20 \mu \mathrm{M})$, a blocker of GABA reuptake transporter type-1 (GAT-1), the CNS expression of which is high in the striatum relative to other subcortical regions (Augood et al., 1995; Kirmse et al., 2008). Tiagabine resulted in a significant decrease in eEPSC amplitude at D1 $(+)$ and D1 $(-)$ MSNs (Fig. 7A-C,F; D1 $(+): 62.00 \pm 3.61 \%, n=5, p=0.0143$; $\mathrm{D} 1(-): 63.67 \pm 5.13 \%, n=6, p=0.00244)$. To determine whether this effect was due to $\mathrm{GABA}_{\mathrm{B}} \mathrm{R}$ heteroreceptor function, we incorporated SCH 50911 into the superfusate before the application of tiagabine. SCH 50911 significantly decreased the tiagabine-induced decrease in eEPSC amplitude in both MSN subtypes (Fig. 7D, F; D1(+) SCH: $88.93 \pm 10.16 \%, n=9$, oneway RM ANOVA, tiagabine effect: $F_{(3,19)}=13.03, p=0.0009$; Sidak's post hoc analysis, ACSF vs SCH: $p=0.0256$; D1 $(-) \mathrm{SCH}$ : $88.57 \pm 5.60 \%, n=10$, one-way RM ANOVA, tiagabine effect: $F_{(3,20)}=18.66, p<0.0001$; Sidak's post hoc analysis, ACSF vs SCH: $p=0.0134)$. If neuronal GAT-1 blockade promotes heterosynaptic crosstalk between GABA- and glutamatergic synapses via $G_{A B A} R$, then CGP 7930, a potent, well characterized $\mathrm{GABA}_{\mathrm{B}} \mathrm{R}$-positive allosteric modulator (PAM; Adams and Lawrence, 2007), should enhance the tiagabine-induced decrease in eEPSC amplitude. Indeed, prior application of CGP 7930 (30 $\mu \mathrm{M})$ enhanced the tiagabine-induced decrease in eEPSC amplitude at $\mathrm{D} 1(+)$ and $\mathrm{D} 1(-)$ MSN synapses (Fig. 7E,F; D1 (+) CGP: $42.81 \pm 3.51 \%, n=5$, one-way RM ANOVA; Sidak's post hoc analysis, ACSF vs CGP: $p=0.0486$; D1(-) CGP: $44.77 \pm$ $4.26 \%, n=7$; Sidak's post hoc analysis, ACSF vs CGP: $p=$ 0.0144 ). CGP 7930 alone had no effect on basal eEPSC amplitude at either MSN subtype (data not shown), consistent with a lack of effect of SCH 50911 alone on basal eEPSC amplitude. These findings suggest that elevations in GAT-1-regulated GABA levels in the NAc core modulate glutamatergic transmission onto D1(+) and $\mathrm{D} 1(-) \mathrm{MSN}$ via $\mathrm{GABA}_{\mathrm{B}} \mathrm{R}$. 

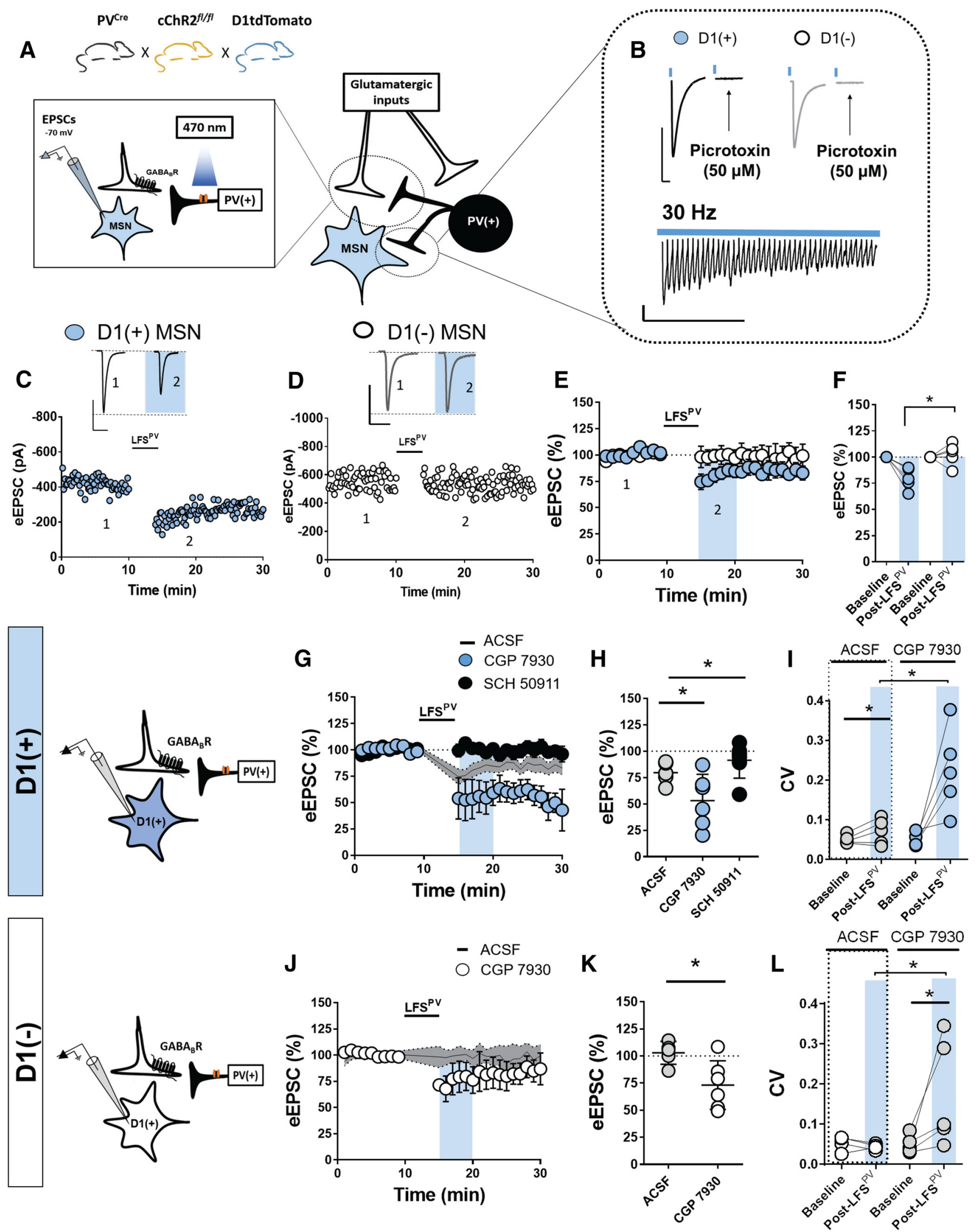

Figure 8. PV-expressing interneurons preferentially decrease glutamatergic transmission onto $D 1(+)$ MSNs via heterosynaptic GABA $R$ signaling. $A$, Left: model depicting breeding scheme of triple transgenic mouse line used to examine heterosynaptic plasticity in the NAc core. Right: synaptic model of heterosynaptic electrophysiological configuration of eEPSCs at D1(+) and D1( - ) MSN synapses obtained via voltage-clamp at $-70 \mathrm{mV}$. PV-INs were stimulated optically at $30 \mathrm{~Hz}$ for $5 \mathrm{~min}$. B, Top, Representative traces of PTX ( $50 \mu \mathrm{M}$ )-sensitive olPSCs recorded in D1 ( + ) and D1(-) MSNs. Scale bar, $300 \mathrm{pA} / 50 \mathrm{~ms}$. Bottom, High-fidelity train of olPSCs delivered at $30 \mathrm{~Hz}$ recorded in MSNs. Scale bar, $30 \mathrm{pA} / 0.5 \mathrm{~s}$. C, D, Representative experiments and traces of eESPCs obtained from D1(+) MSNs (blue circles) and D1(-) MSNs (open circles) pre- and post-LFS ${ }^{\text {PV }}$ (in PTX). LFS denotes optically-evoked stimulation at $30 \mathrm{~Hz}$ for 5 min. (Figure legend continues.) 
Parvalbumin-expressing interneurons preferentially decrease glutamatergic transmission onto $\mathrm{D} 1(+) \mathrm{MSNs}$ via heterosynaptic $\mathrm{GABA}_{\mathrm{B}} \mathrm{R}$ signaling

Although various sources of GABA exist in the NAc, we hypothesized that fast-spiking interneurons, the majority of which express the $\mathrm{Ca}^{2+}$-binding protein parvalbumin, contribute to elevations in extrasynaptic GABA concentration as a consequence of their fast-spiking activity. PV-INs in the NAc coordinate MSN spiking activity through feedforward inhibition, wherein glutamatergic synapses onto MSNs collateralize onto nearby PV-INs, which exert robust GABAergic control over MSN output (Wright et al., 2017; Yu et al., 2017; Scudder et al., 2018). Compared with MSNs and other GABAergic interneuron subtypes in the NAc, PV-INs receive stronger and more extensive excitatory input from afferents that drive MSN activity, providing them with greater temporal authority over information propagated through the NAc (Yu et al., 2017; Scudder et al., 2018). Furthermore, the lack of tonic $\mathrm{GABA}_{\mathrm{B}} \mathrm{R}$ activity at glutamatergic synapses suggests a neuronal source of GABA driven by acute shifts in circuit activity. To determine whether PV-INs exert heterosynaptic control over glutamatergic synapses onto D1 $(+)$ and D1(-) MSNs, we bred PV-Cre mice, in which Cre recombinase expression is driven by the PV promoter, with Ai32 conditional ChR2 (cChR2) and D1tdTomato BAC transgenic mouse lines, generating $\mathrm{PV}^{\mathrm{Cre}}$ mice (Fig. $8 \mathrm{~A}$ ). This breeding strategy confers optogenetic control over PV-expressing cells in the NAc, which are GABAergic PV-INs. Indeed, oIPSCs recoded from D1 $(+)$ and D1 $(-)$ MSNs were abolished by PTX $(50 \mu \mathrm{M})$, indicating that PV-IN-to-MSN transmission in the NAc core is mediated by GABA $_{\mathrm{A}} \mathrm{R}$ (Fig. $8 B$; D1 $(+$ ) PTX: $4.5 \pm 3.11 \%, n=5, p=0.8851$; $\mathrm{D} 1(-) 5.96 \pm 2.07 \%, n=6, p=0.6500)$.

To determine whether PV-IN activity modulates glutamatergic transmission onto $\mathrm{D} 1(+)$ and $\mathrm{D} 1(-) \mathrm{MSN}$, we prepared acute brain slices from $\mathrm{PV}^{\mathrm{Cre}}$ mice and recorded eEPSCs from $\mathrm{D} 1(+)$ and D1 (-) MSNs in PTX-containing ACSF. PV-INs were stimulated optically at $30 \mathrm{~Hz}$ to resemble a PV-IN-directed, lowrange gamma frequency stimulation $\left(\mathrm{LFS}^{\mathrm{PV}}\right.$ ) pattern. Before using this induction protocol, we first wanted to confirm that optical excitation of PV-INs at $30 \mathrm{~Hz}$ yielded high-fidelity oIPSCs in MSNs. Indeed, LFS $^{\mathrm{PV}}$ resulted in oIPSCs in MSNs throughout the induction period, indicating that $\mathrm{ChR} 2(\mathrm{H} 134 \mathrm{R})$ is a suitable opsin for these experiments (Fig. 8B). Following a stable $10 \mathrm{~min}$ eEPSC baseline, LFS $^{\text {PV }}$ was delivered for $5 \mathrm{~min}$, after which eEP$\mathrm{SCs}$ were recorded up to $30 \mathrm{~min}$ post-LFS. LFS ${ }^{\mathrm{PV}}$ resulted in a significant decrease in eEPSC amplitude at D1 $(+)$ but not D1 $(-)$ MSNs that was accompanied by an increase in $\mathrm{CV}$, consistent with a presynaptic locus of action (Fig. 8C-F; D1(+): $79.71 \pm$ $5.12 \%, n=5, p=0.0481 ; \mathrm{D} 1(-): 102.86 \pm 5.26 \%, n=5, p=$ $0.5762 ; \mathrm{CV}=\mathrm{D} 1(+)$ baseline: $0.05 \pm 0.01, \mathrm{D} 1(+)$ post-LFS ${ }^{\mathrm{PV}}$ : $0.072 \pm 0.015, n=5, p=0.0352$; D1 $(-)$ baseline: $0.05 \pm 0.01$, $\mathrm{D} 1(-)$ post-LFS $\left.{ }^{\mathrm{PV}}: 0.04 \pm 0.004, n=5, p=0.3665\right)$. The effect of LFS ${ }^{\mathrm{PV}}$ on eEPSC amplitude was significantly different between $\mathrm{D} 1(+)$ and D1(-) MSNs (two-way RM ANOVA, LFS ${ }^{\mathrm{PV}}-\mathrm{MSN}$

(Figure legend continued.) Scale bar, $200 \mathrm{pA} / 50 \mathrm{~ms}$. $\boldsymbol{E}$, Time course of normalized eEPSCs obtained from D1 $(+)$ and D1 (-) MSNs pre- and post-LFS ${ }^{\text {PV }} . \boldsymbol{F}$, Graph of average eEPSC amplitude post-LFS (blue; $t=15-20 \mathrm{~min}$ ). $\boldsymbol{G}, \boldsymbol{H}$, Time course summary and graph of normalized eEPSCs obtained from D1 (+) MSNs in normal ACSF (line), SCH 50911 (black dots), and CGP 7930 (blue). $I$, Graph depicting CV post-LFS ${ }^{\mathrm{PV}}(t=15-20 \mathrm{~min})$ in normal aCSF and CGP7930 $(n=4)$. $\boldsymbol{J}, \boldsymbol{K}$, Time course summary and graph of normalized eEPSCs obtained from D1(+) MSNs in normal aCSF (line) and CGP 7930 (open circles). L, Graph depicting CV post-LFS ${ }^{\mathrm{PV}}(t=15-20$ $\mathrm{min}$ ) in normal ACSF and (GP 7930. Error bars indicate SEM. ${ }^{*} p<0.05$. subtype interaction: $\left.F_{(1,4)}=14.48, p=0.0170\right)$. To determine whether this plasticity was mediated by $\mathrm{GABA}_{\mathrm{B}} \mathrm{R}, \mathrm{SCH} 50911$ was incorporated into the ACSF bath before the induction protocol. SCH 50911 completely abolished the LFS ${ }^{\mathrm{PV}}$-induced depression of eEPSC amplitude at D1(+) MSN synapses (Fig. 8G-I; D1 (+) SCH: $91.46 \pm 7.63 \%, n=6, p=0.2751)$. Furthermore, prior application of CGP 7930 enhanced the LFS ${ }^{\mathrm{PV}}$-induced depression at D1 $(+)$ MSNs and unmasked a significant depression in $\mathrm{D} 1(-)$ MSNs that was accompanied by an increase in CV (Fig. $8 G-L$; D1 (+) CGP: $48.14 \pm 8.56 \%, n=6$, one-way RM ANOVA, Sidak's post hoc analysis ACSF vs CGP: $p=0.0043$; D1( - ) CGP: $73 \pm 10.03 \%, n=6, p=0.0325 ; C V=\mathrm{D} 1(+)$ baseline: $0.048 \pm$ $0.008, \mathrm{D} 1(+)$ post-LFS ${ }^{\mathrm{PV}}$ CGP: $0.226 \pm 0.053, n=5, p=0.0069$; $\mathrm{D} 1(-)$ baseline: $0.048 \pm 0.11, \mathrm{D} 1(-)$ post-LFS $^{\mathrm{PV}}$ CGP: $0.18 \pm$ $0.067, n=7, p=0.0475)$. These data indicate that PV-INs can heterosynaptically regulate glutamatergic transmission onto $\mathrm{D} 1(+)$ MSNs and, less so, D1(-) MSNs by targeting presynaptically-expressed $\mathrm{GABA}_{\mathrm{B}} \mathrm{R}$, identifying a novel arm within feedforward inhibitory microcircuits in the NAc core.

PV-IN-to-MSN synapses in the striatum maintain synaptic efficacy across a broad dynamic range of firing frequencies (Gittis et al., 2010). We hypothesized that this property may permit heterosynaptic crosstalk between PV-INs and glutamate terminals without altering GABAergic transmission at PV-IN-to-MSN synapses. To address this, we recorded oIPSCs elicited from PVINs in D1 (+) and D1 (-) MSNs (Fig. 9A). We first tested whether $\mathrm{GABA}_{\mathrm{B}} \mathrm{R}$ autoregulates PV-IN-to-D1(+) and D1(-) MSN synapses. Interestingly, only a subset of PV-IN-to-MSN synapses were responsive to $\mathrm{BAC}[\mathrm{BAC}(+)]$, with $\mathrm{BAC}(+)$ synapses exhibiting a significant decrease in oIPSC amplitude at both MSN subtypes and $\mathrm{BAC}(-)$ synapses exhibiting no change in oIPSC amplitude. Subsequent application of SCH 50911 incompletely reversed oIPSC amplitude to baseline at $\mathrm{BAC}(+)$ synapses, indicating the presence of inhibitory long-term depression at a subset of synapses (Fig. 9B-E; BAC $(+)$ cells $=\mathrm{D} 1(+)$ BAC: $41.73 \pm$ $6.03 \%, \mathrm{D} 1(+) \mathrm{SCH}: 58.76 \pm 3.49 \%, n=4$, one-way $\mathrm{RM}$ ANOVA, drug effect: $F_{(2,10)}=70.94, p<0.0001$, Sidak's post hoc analysis, baseline vs BAC: $p<0.001$, vs SCH: $p<0.001$; D1 $(-)$ BAC: $38.96 \pm 6.17 \%, \mathrm{D} 1(-) \mathrm{SCH}: 63.09 \pm 5.37 \%, n=4$, oneway RM ANOVA, drug effect: $F_{(2,10)}=93.97, p<0.0001$, Sidak's post hoc analysis, baseline vs BAC: $p<0.001$, vs SCH: $p<0.001$; $\mathrm{BAC}(-)$ cells $=\mathrm{D} 1(+): 98.42 \pm 2.76 \%, n=3$ of 11 cells, $p=$ 0.1169 ; D1 $(-): 99.36 \pm 2.86 \%, n=3$ of 9 cells, $p=0.2690)$. We next asked whether $\mathrm{GABA}_{\mathrm{B}} \mathrm{R}$ activity tonically inhibits PV-IN-to$\mathrm{D} 1(+)$ and $\mathrm{D} 1(-) \mathrm{MSN}$ synapses via presynaptic autoreceptor function. SCH 50911 added to the ACSF following a $10 \mathrm{~min}$ oIPSC baseline did not significantly alter oIPSC amplitude at $\mathrm{D} 1(+)$ or D1(-) MSN synapses (Fig. 9F, G; D1(+): $100.05 \pm$ 7.64\%, $n=4, p=0,9981$; D1 $(-) 101.56 \pm 4.23 \%, n=5, p=$ $0.6900)$. Given these findings, we predicted that $\mathrm{LFS}^{\mathrm{PV}}$ would not elicit a $\mathrm{GABA}_{\mathrm{B}} \mathrm{R}$-dependent change in synaptic strength at PVIN-to-MSN synapses. Indeed, GABAergic transmission at PVIN-to-MSN (pooled) synapses remained completely unchanged 40 min post-LFS $^{\mathrm{PV}}$ (Fig. $9 \mathrm{H}, \mathrm{I}$; pooled MSNs: $103.56 \pm 7.62 \%$, $n=4, p=0.3138)$. Together, these data suggest that PV-INs are well suited to functionally regulate glutamatergic transmission via $\mathrm{GABA}_{\mathrm{B}}$ heteroreceptors on glutamate terminals in the NAc core.

\section{Discussion}

We elucidate cell-type-specific and microcircuit-specific mechanisms by which $\mathrm{GABA}_{\mathrm{B}} \mathrm{R}$ dynamically regulates glutamatergic synapses in the NAc core. We report that presynaptically- 
A
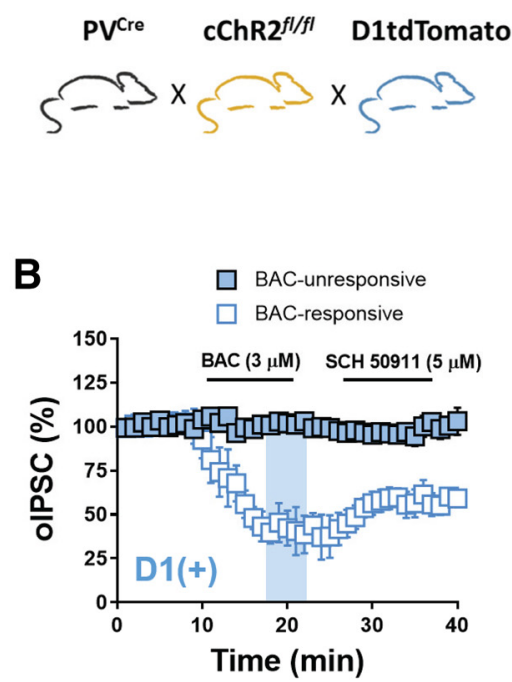

D

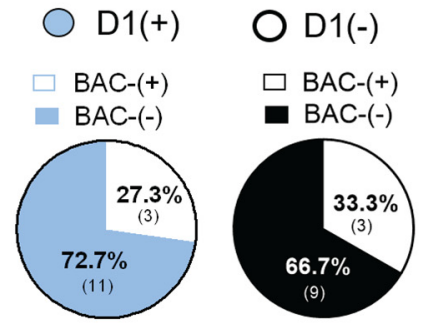

$\mathbf{F}$

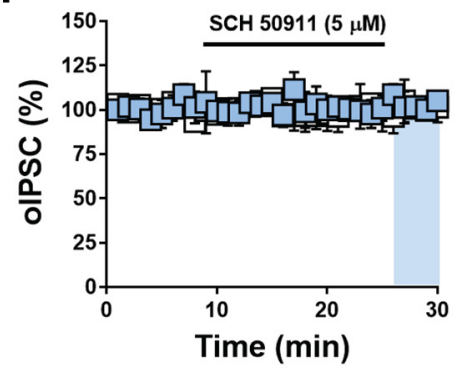

H

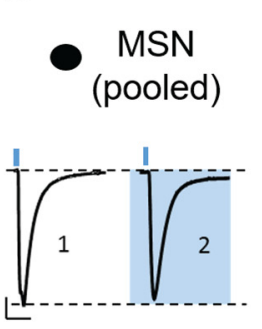

I
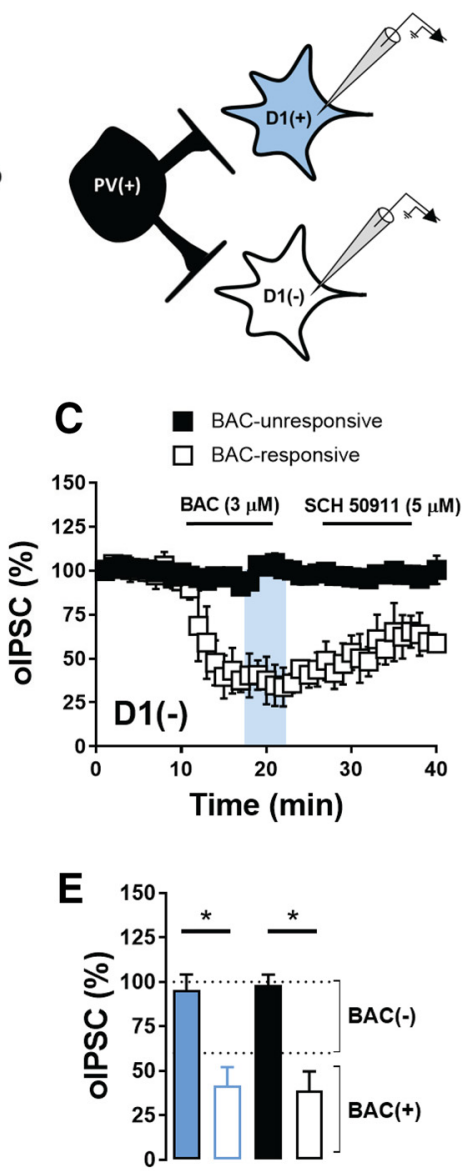

G

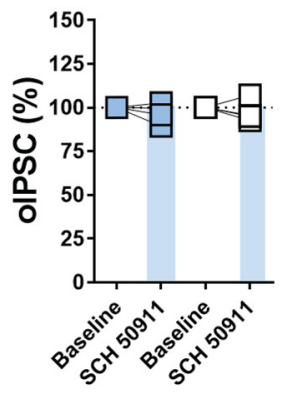

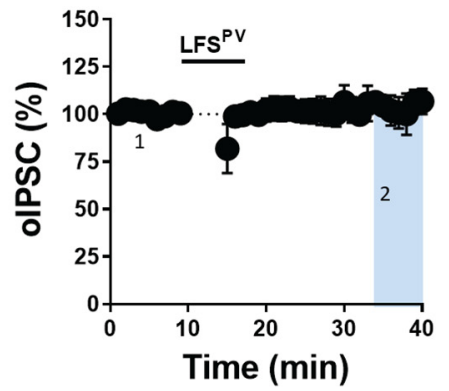

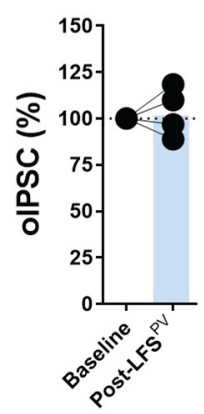

Figure 9. GABAergic transmission at PV-IN-to-D1(+) and D1(-) MSN synapses is largely BAC-insensitive and unchanged by LFS. $A$, Schematic of breeding scheme and electrophysiological configuration permitting optogenetic examination of GABAergic transmission at PV-IN-to-D1(+) MSN synapses (blue squares) and D1(-) MSN synapses (black squares) in the NAc core. $\boldsymbol{B}$, Time course summary at PV-IN-to-D1(+) MSN synapses showing that BAC decreases olPSC amplitude to elicit inhibitory long-term depression at a minority of synapses [BAC-response $(B A C+)$, open squares; $B A C$-unresponsive $(B A C-)$, blue filled squares]. $C$, Time course summary at PV-IN-to-D1(-) MSN synapses showing that BAC decreases olPSC amplitude to elicit inhibitory longterm depression at a minority of synapses (BAC+, open squares; $B A C-$, black filled squares). $\boldsymbol{D}$, Pie chart representation of $\mathrm{BAC}+/ \mathrm{BAC}$ - synapses onto D1(+) and D1(-) MSNs. Note that the pie-chart data were obtained following pharmacological characterization of $\mathrm{BAC}(+)$ and $\mathrm{BAC}(-)$ at PV-IN-to-MSN synapses. $\boldsymbol{E}$, Quantification of average olPSC amplitude depicting

expressed $\mathrm{GABA}_{\mathrm{B}} \mathrm{R}$ activation elicits a robust decrease in glutamatergic synaptic transmission onto $\mathrm{D} 1(+)$ and $\mathrm{D} 1(-)$ MSNs by engaging a non-canonical signaling mechanism that is distinct from other $\mathrm{G}_{\mathrm{i} / \mathrm{o}}$-coupled GPCRs in the NAc, including $\mathrm{CB}_{1} \mathrm{R}$ and group II mGluRs. Instead, $\mathrm{GABA}_{\mathrm{B}} \mathrm{R}$ activity interferes with vesicular exocytosis in a SNAP-25-dependent manner. Furthermore, we show that $\mathrm{GABA}_{\mathrm{B}}$ heteroreceptors at $\mathrm{D} 1(+)$ MSN synapses are preferentially recruited by PV-INs within feedforward inhibitory microcircuits. Alongside data showing a lack of $\mathrm{GABA}_{\mathrm{B}} \mathrm{R}$ tone at glutamatergic synapses, these data offer rigorous support for a new, activity-dependent $G_{A B A} R$ contingent arm within feedforward circuits in the NAc core.

Presynaptic $\mathrm{GABA}_{\mathrm{B}} \mathrm{R}$ recruits a non-canonical, SNAP-25-dependent signaling mechanism to regulate glutamatergic transmission in the NAc core

We find that $\mathrm{GABA}_{\mathrm{B}} \mathrm{R}$ activation elicits a robust decrease in synaptic efficacy at glutamatergic synapses onto $\mathrm{D} 1(+)$ and D1(-) MSNs. Following pharmacological examination of $\mathrm{GABA}_{\mathrm{B}} \mathrm{R}$ function, our findings suggest that $G_{B B A} R$ recruits a signaling mechanism that is $\mathrm{N}$ - and $\mathrm{P} / \mathrm{Q}-$ type VGCC, Kir, mGluR, and AC/cAMPindependent, suggesting that $\mathrm{GABA}_{\mathrm{B}} \mathrm{R}$ recruits a non-canonical signaling pathway at these synapses. Anomalous $\mathrm{GABA}_{\mathrm{B}} \mathrm{R}$ function has been described in regions where the synaptic effects of $\mathrm{BAC}$ are insensitive to $\mathrm{G}_{\mathrm{i} / \mathrm{o}}$-GPCR-disabling agents, such as pertussis toxin or NEM (Colmers and Pittman, 1989). We hypothesized that $G_{A B A} R$ directly interferes with vesicular release machinery, such as membrane-associated t-SNARE, SNAP-25, to reduce glutamate release probability onto MSNs. SNAP-25 facilitates transmitter exocytosis by binding $\mathrm{Ca}^{2+}$-sensing SNARE protein, synaptotagmin, to establish ternary SNARE complexes that authorize vesicular release (Wells et al., 2012; Zurawski et al., 2019).

$\leftarrow$

separation between $B A C+$ and BAC- PV-IN-to-MSN synapses. $\boldsymbol{F}, \mathbf{G}$, Time course summary and average oIPSC amplitude showing that bath application of $\mathrm{ABBA}_{\mathrm{B}}$ Rantagonist, $\mathrm{SCH}$ 50911, alone does not alter olPSC amplitude at PV-IN-toD1 (+) and D1 (-) MSN synapses. $\boldsymbol{H}$, Representative traces of olPSCs pre- and post-LFS ${ }^{\mathrm{PV}}$ at pooled MSN synapses. I, Time course summary and quantification of average oIPSC amplitude pre- and post-LFS ${ }^{\mathrm{PV}}$ showing that LFS ${ }^{\mathrm{PV}}$ does not alter oIPSC amplitude at PV-IN-to-MSN (pooled) synapses. Error bars indicate SEM. ${ }^{*} p<0.05$. 
The C-terminally-located botulinum toxin type-A cleavage site of SNAP-25 has previously been shown to mediate the inhibitory actions of G $\beta \gamma$ on SNAP-25 (Gerachshenko et al., 2005). Thus, we used SNAP2 $5 \Delta 3$ transgenic mice partially deficient $(\sim 47 \%)$ in the SNAP-25-G $\beta \gamma$ interaction. Consistent with reduced synaptic efficacy of $\mathrm{GABA}_{\mathrm{B}} \mathrm{R}$, the actions of BAC were dosedependently reduced in SNAP25 33 mutant mice. While targeted mutations in SNAP-25 will affect other neuromodulatory systems in the NAc, the BAC-induced reduction in mEPSC frequency supports a direct synaptic effect of $G_{A B A} R$ on glutamatergic transmission. The pronounced increase in PPR induced by BAC was also abolished in SNAP25 33 mice, strongly supporting the hypothesis that $\mathrm{GABA}_{\mathrm{B}} \mathrm{R}$-induced decrease in glutamate release probability is partially mediated by the SNAP-25-G $\beta \gamma$ interaction.

Several key findings also support a VGCC-independent interaction with vesicular release machinery. Low $\mathrm{Ca}^{2+}$ ACSF and pharmacological blockade of $\mathrm{N}$ - and P/Q-type VGCCs failed to occlude the effects of BAC on glutamatergic transmission. The nonlinear relationship between VGCCs and transmitter release at corticostriatal synapses complicates the interpretation of this finding, as a modest reduction in presynaptic $\mathrm{Ca}^{2+}$ influx can substantially impact neurotransmitter release (Kupferschmidt and Lovinger, 2015). Therefore, we examined the functional interaction between GABA $_{B} R$ and VGCC-targeting $G_{i / o}$-coupled GPCRs in the NAc, such as $\mathrm{CB}_{1} \mathrm{R}$ and group II mGluRs. Presynaptically-expressed $\mathrm{CB}_{1} \mathrm{R}$ and mGluRs trigger short- and long-term plasticity can be attributed in part to their actions on presynaptic $\mathrm{Ca}^{2+}$ entry via VGCCs. For example, group II mGluRs in the NAc trigger presynaptic LTD by attenuating downstream P/Q-type VGCC function (Robbe et al., 2002). Similarly, activity-dependent release of eCBs can transiently activate presynaptic $\mathrm{CB}_{1} \mathrm{Rs}$ on glutamate terminals to elicit VGCCdependent reductions in neurotransmitter release (Hoffman and Lupica, 2000; Kreitzer and Regehr, 2001). Our data collectively suggest that $\mathrm{GABA}_{\mathrm{B}} \mathrm{R}$ recruits different intracellular effectors than either group II mGluRs or $\mathrm{CB}_{1} \mathrm{R}$, corroborating the hypothesis that $\mathrm{GABA}_{\mathrm{B}} \mathrm{R}$ mobilizes $\mathrm{G} \beta \gamma$ to interact directly with exocytotic machinery at the presynaptic active zone.

Blocking $\mathrm{K}_{\mathrm{V}}$ channels significantly attenuated and reversed the actions of $\mathrm{GABA}_{\mathrm{B}} \mathrm{R}$, consistent with previous studies showing that $\mathrm{G} \beta \gamma$-SNARE interactions can be overcome by increasing presynaptic $\mathrm{Ca}^{2+}$ levels (Wells et al., 2012; Li et al., 2016). Although we cannot definitively rule out $\mathrm{GABA}_{\mathrm{B}} \mathrm{R}$-induced changes in $\mathrm{K}^{+}$channel function, the observation that $\mathrm{GABA}_{B} \mathrm{R}$ activity returns to normal in 4-AP-containing low- $\mathrm{Ca}^{2+} \mathrm{ACSF}$, is resistant to extracellular $\mathrm{Ba}^{2+}$ application, and produces no detectible change in PPR following 4-AP treatment points to a 4 -AP-induced enhancement in presynaptic $\mathrm{Ca}^{2+}$ conductance. Although it is possible that $\mathrm{GABA}_{\mathrm{B}} \mathrm{R}$ initiates functionally redundant mechanisms to reduce glutamate release, this hypothesis is less likely given that the effects of BAC on eEPSC amplitude remained intact following each pharmacological manipulation. Together, we propose a novel mechanism by which $\mathrm{GABA}_{\mathrm{B}} \mathrm{R}$ in the NAc core reduces presynaptic glutamate release probability downstream of VGCCs by interfering with the assembly of core SNARE complexes in a SNAP-25-dependent manner.

\section{PV-INs heterosynaptically regulate glutamatergic transmission via $\mathrm{GABA}_{\mathrm{B}} \mathrm{R}$}

Although heterosynaptic regulation of GABAergic synapses by glutamate has been characterized in the striatum, the reverse relationship in which GABA regulates glutamatergic transmission has not been demonstrated (Mathur et al., 2013; Patton et al., 2019). We report that optogenetic stimulation of $\mathrm{PV}(+)$ cells reduces glutamatergic transmission onto $\mathrm{D} 1(+)$ and, less so, $\mathrm{D} 1(-)$ MSNs in a $\mathrm{GABA}_{\mathrm{B}} \mathrm{R}$-dependent manner, offering physiological context for $\mathrm{GABA}_{\mathrm{B}}$ heteroreceptor function within the NAc. This finding is striking for several reasons. First, striatal PV-INs form monosynaptic connections with MSNs at somatic and proximal dendritic domains, whereas glutamatergic afferents target distal dendrites (Hu et al., 2014; Yu et al., 2017). The privileged anatomical positioning of PV-IN-to-MSN synapses confers optimal GABAergic control over MSN spiking activity, supporting the role of PV-INs in feedforward inhibition. Second, PV-INs, unlike somatostatin-expressing (SST) INs, lack autonomous action potential (AP) firing that could contribute to tonic $\mathrm{GABA}_{\mathrm{B}}$ heteroreceptor function (Smith et al., 2017; Trouche et al., 2019). However, PV-INs receive significantly greater excitatory innervation than SOM-INs and sustain afferent-evoked firing rates of up to $250 \mathrm{~Hz}$, indicating that acute shifts in circuit activity are likely to recruit PV-INs over other GABAergic cell types in the NAc (Scudder et al., 2018; Tepper et al., 2018; Trouche et al., 2019). SST-INs also exhibit biophysical limitations that prevent them from responding to time-locked changes in glutamatergic transmission, including a lower AP frequency, prolonged latency to spike, and accommodating AP firing pattern (Scudder et al., 2018; Tepper et al., 2018). Whereas tonic $\mathrm{GABA}_{\mathrm{A}} \mathrm{R}$ and $\mathrm{GABA}_{\mathrm{B}} \mathrm{R}$ activity is observed at heterosynaptic loci on DA terminals in the dorsal striatum, NAc DA release is comparatively unaffected by $\mathrm{GABA}_{\mathrm{B}} \mathrm{R}$ blockade (Tritsch et al., 2014; Melchior et al., 2015; Lopes et al., 2019). Similarly, we do not detect $\mathrm{GABA}_{\mathrm{B}} \mathrm{R}$ tone at glutamatergic synapses onto $\mathrm{D} 1(+)$ or $\mathrm{D} 1(-) \mathrm{MSN}$, supporting a distinct role for GABAergic neurons requiring afferent excitatory input to fire. Therefore, PV-INs may be better equipped than other GABAergic cell types in the NAc to modulate activity-dependent increases in glutamatergic activity.

PV-INs entrain principal neuron output via gamma frequency oscillations $(25-100 \mathrm{~Hz})$ that are sustained by the coordinated recruitment of electrically-connected PV-INs (Hu et al., 2014). We elected to activate PV-INs at $30 \mathrm{~Hz}\left(\mathrm{LFS}^{\mathrm{PV}}\right)$ to resemble a physiologically relevant gamma frequency stimulation pattern that can be achieved with the transgenically-encoded opsin, ChR2(H134R). Our data suggest that LFS ${ }^{\text {PV }}$ for 5 min is sufficient to heterosynaptically target $\mathrm{GABA}_{\mathrm{B}} \mathrm{R}$ at glutamatergic synapses onto $\mathrm{D} 1(+)$ MSNs. Interestingly, we find that $\mathrm{LFS}^{\mathrm{PV}}$ targets $\mathrm{GABA}_{\mathrm{B}} \mathrm{R}$ at synapses onto $\mathrm{D} 1(-)$ MSNs only in the presence of a $G_{A B A} R$ PAM, suggesting that LFS $^{\text {PV }}$ may be subthreshold to elicit changes in glutamatergic transmission at synapses ono D1(-) MSNs. One possibility is that PV-IN-to$\mathrm{D} 1(+)$ and $\mathrm{D} 1(-) \mathrm{MSN}$ synapses are differentially regulated by $\mathrm{GABA}_{\mathrm{B}} \mathrm{R}$, with synapses onto $\mathrm{D} 1(-)$ MSNs exhibiting greater $\mathrm{GABA}_{\mathrm{B}} \mathrm{R}$-dependent autoinhibitory feedback than synapses onto $\mathrm{D} 1(+)$ MSNs. Differences in autoreceptor function at these synapses would limit the efficacy with which prolonged PV-IN stimulation elevates extracellular GABA levels. However, the majority of PV-IN-to-D1(+) and D1(-) MSN synapses were BACinsensitive and LFS $^{\mathrm{PV}}$ of oIPSCs failed to elicit homosynaptic plasticity at PV-IN-to-MSN synapses. Having ruled out intrinsic mechanisms at PV-IN-to-MSN synapses, the most probable explanation is a synapse-specific difference in GABA sensitivity. This hypothesis is strongly supported by the BAC dose-response relationship in which glutamatergic synapses onto D1(+) MSNs exhibited increased sensitivity to BAC at lower concentrations (200-600 nM) relative to D1(-) MSNs. Another intriguing possibility is whether differences in GABA reuptake kinetics between 
D1(+) and D1(-) synapses create synapse-specific microdomains that modulate glutamatergic inputs onto distinct cell types in the NAc. Future studies will be needed to elucidate fully the intricate mechanisms by which PV-INs sculpt cell-type-specific circuit output in the NAc core.

\section{Concluding remarks}

The NAc coordinates motivated behaviors by integrating PV-INdirected inhibitory networks with glutamatergic inputs from various salience-encoding brain regions. While $G_{A B A} R$ function is well characterized at upstream loci within the mesolimbic reward network, a comprehensive analysis of $\mathrm{GABA}_{\mathrm{B}}$ heteroreceptor function in the NAc is lacking. Here, we revise and expand knowledge on the role of $\mathrm{GABA}_{\mathrm{B}} \mathrm{R}$ function within PV-INembedded feedforward microcircuits in the NAc core. Our findings rigorously support a novel mechanism by which $\mathrm{GABA}_{\mathrm{B}} \mathrm{R}$ modulates glutamatergic transmission and define an activitydependent source of GABA within PV-IN-embedded feedforward circuits. Understanding the role of $G_{A B A} R$ within NAc microcircuits paints a more complete picture of how $G_{A B A} R$ specific pharmacological agents can be used to treat neuropsychiatric disorders characterized by aberrant motivational states, including addiction, major depressive disorder, and autism (Cousins et al., 2002; Kahn et al., 2009; Jacobson et al., 2018; Stoppel et al., 2018; Pisansky et al., 2019).

\section{References}

Adams CL, Lawrence AJ (2007) CGP7930: a positive allosteric modulator of the GABAB receptor. CNS Drug Rev 13:308-316.

Augood SJ, Herbison AE, Emson PC (1995) Localization of GAT-1 GABA transporter mRNA in rat striatum: cellular coexpression with GAD67 mRNA, GAD67 immunoreactivity, and parvalbumin mRNA. J Neurosci 15:865-874.

Castillo PE, Younts TJ, Chávez AE, Hashimotodani Y (2012) Endocannabinoid signaling and synaptic function. Neuron 76:70-81.

Colmers WF, Pittman QJ (1989) Presynaptic inhibition by neuropeptide Y and baclofen in hippocampus: insensitivity to pertussis toxin treatment. Brain Res 498:99-104.

Cousins MS, Roberts DC, de Wit H (2002) GABAB receptor agonists for the treatment of drug addiction: a review of recent findings. Drug Alcohol Depend 65:209-220.

Cruz HG, Ivanova T, Lunn ML, Stoffel M, Slesinger PA, Lüscher C (2004) Bi-directional effects of GABAB receptor agonists on the mesolimbic dopamine system. Nat Neurosci 7:153-159.

Di Ciano P, Everitt BJ (2003) The GABAB receptor agonist baclofen attenuates cocaine-and heroin-seeking behavior by rats. Neuropsychopharmacology 28:510-518.

Dobbs LK, Kaplan AR, Lemos JC, Matsui A, Rubinstein M, Alvarez VA (2016) Dopamine regulation of lateral inhibition between striatal neurons gates the stimulant actions of cocaine. Neuron 90:1100-1113.

Edwards NJ, Tejeda HA, Pignatelli M, Zhang S, McDevitt RA, Wu J, Bass CE, Bettler B, Morales M, Bonci A (2017) Circuit specificity in the inhibitory architecture of the VTA regulates cocaine-induced behavior. Nat Neurosci 20:438-448.

Gerachshenko T, Blackmer T, Yoon EJ, Bartleson C, Hamm HE, Alford S (2005) G $\beta \gamma$ acts at the C terminus of SNAP-25 to mediate presynaptic inhibition. Nat Neurosci 8:597-605.

Gittis AH, Nelson AB, Thwin MT, Palop JJ, Kreitzer AC (2010) Distinct roles of GABAergic interneurons in the regulation of striatal output pathways. J Neurosci 30:2223-2234

Grueter BA, Brasnjo G, Malenka RC (2010) Postsynaptic TRPV1 triggers cell type-specific long-term depression in the nucleus accumbens. Nat Neurosci 13:1519-1525.

Heifets BD, Chevaleyre V, Castillo PE (2008) Interneuron activity controls endocannabinoid-mediated presynaptic plasticity through calcineurin. Proc Natl Acad Sci U S A 105:10250-10255.

Hoffman AF, Lupica CR (2000) Mechanisms of cannabinoid inhibition of $\mathrm{GABA}_{\mathrm{A}}$ synaptic transmission in the hippocampus. J Neurosci 20: $2470-2479$
Hotsenpiller G, Wolf ME (2003) Baclofen attenuates conditioned locomotion to cues associated with cocaine administration and stabilizes extracellular glutamate levels in rat nucleus accumbens. Neuroscience 118:123-134.

Hu H, Gan J, Jonas P (2014) Fast-spiking, parvalbumin ${ }^{+}$GABAergic interneurons: from cellular design to microcircuit function. Science.345: 1255263.

Iremonger KJ, Bains JS (2009) Retrograde opioid signaling regulates glutamatergic transmission in the hypothalamus. J Neurosci 29:7349-7358.

Jacobson LH, Vlachou S, Slattery DA, Li X, Cryan JF (2018) The gammaaminobutyric acid B receptor in depression and reward. Biol Psychiatry 83:963-976

Joffe ME, Grueter BA (2016) Cocaine experience enhances thalamoaccumbens $N$-methyl-D-aspartate receptor function. Biol Psychiatry 80:671-681.

Kahn R, Biswas K, Childress AR, Shoptaw S, Fudala PJ, Gorgon L, Montoya I, Collins J, McSherry F, Li SH, Chiang N, Alathari H, Watson D, Liberto J, Beresford T, Stock C, Wallace C, Gruber V, Elkashef A (2009) Multicenter trial of baclofen for abstinence initiation in severe cocainedependent individuals. Drug Alcohol Depend 103:59-64.

Kalivas PW (2009) The glutamate homeostasis hypothesis of addiction. Nat Rev Neurosci 10:561-572.

Kashima DT, Grueter BA (2017) Toll-like receptor 4 deficiency alters nucleus accumbens synaptic physiology and drug reward behavior. Proc Natl Acad Sci U S A 114:8865-8870.

Kirmse K, Dvorzhak A, Kirischuk S, Grantyn R (2008) GABA transporter 1 tunes GABAergic synaptic transmission at output neurons of the mouse neostriatum. J Physiol 586:5665-5678.

Koob GF, Volkow ND (2016) Neurobiology of addiction: a neurocircuitry analysis. The Lancet Psychiatry 3:760-773.

Kreitzer AC, Regehr WG (2001) Retrograde inhibition of presynaptic calcium influx by endogenous cannabinoids at excitatory synapses onto Purkinje cells. Neuron 29:717-727.

Kupferschmidt DA, Lovinger DM (2015) Inhibition of presynaptic calcium transients in cortical inputs to the dorsolateral striatum by metabotropic GABAB and mGlu2/3 receptors. J Physiol 593:2295-2310.

Labouèbe G, Lomazzi M, Cruz HG, Creton C, Luján R, Li M, Yanagawa Y, Obata K, Watanabe M, Wickman K, Boyer SB, Slesinger PA, Lüscher C (2007) RGS2 modulates coupling between GABAB receptors and GIRK channels in dopamine neurons of the ventral tegmental area. Nat Neurosci 10:1559-1568.

Lacey CJ, Boyes J, Gerlach O, Chen L, Magill PJ, Bolam JP (2005) GABAB receptors at glutamatergic synapses in the rat striatum. Neuroscience 136: 1083-1095.

Ladera C, del Carmen Godino M, José Cabañero M, Torres M, Watanabe M, Luján R, Sánchez-Prieto J (2008) Pre-synaptic GABAB receptors inhibit glutamate release through GIRK channels in rat cerebral cortex. J Neurochem 107:1506-1517.

LeGates TA, Kvarta MD, Tooley JR, Francis TC, Lobo MK, Creed MC, Thompson SM (2018) Reward behaviour is regulated by the strength of hippocampus-nucleus accumbens synapses. Nature 564:258-262.

Li G, Liu ZL, Zhang WN, Yang K (2016) Blockade of presynaptic 4 -aminopyridine-sensitive potassium channels increases initial neurotransmitter release probability, reinstates synaptic transmission altered by $\mathrm{GABAB}$ receptor activation in rat midbrain periaqueductal gray. Neuroreport 27:50-55.

Li SM, Yin LL, Ren YH, Pan LS, Zheng JW (2001) GABAB receptor agonist baclofen attenuates the development and expression of d-methamphetamine-induced place preference in rats. Life Sci 70:349-356.

Lim BK, Huang KW, Grueter BA, Rothwell PE, Malenka RC (2012) Anhedonia requires MC4R-mediated synaptic adaptations in nucleus accumbens. Nature 487:183-189.

Lopes EF, Roberts BM, Siddorn RE, Clements MA, Cragg SJ (2019) Inhibition of nigrostriatal dopamine release by striatal $\mathrm{GABA}_{\mathrm{A}}$ and $\mathrm{GABA}_{\mathrm{B}}$ receptors. J Neurosci 39:1058-1065.

Lüscher C, Malenka RC (2011) Drug-evoked synaptic plasticity in addiction: from molecular changes to circuit remodeling. Neuron 69:650-663.

Mathur BN, Tanahira C, Tamamaki N, Lovinger DM (2013) Voltage drives diverse endocannabinoid signals to mediate striatal microcircuit-specific plasticity. Nat Neurosci 16:1275-1283.

Mato S, Lafourcade M, Robbe D, Bakiri Y, Manzoni OJ (2008) Role of the cyclic-AMP/PKA cascade and of P/Q-type $\mathrm{Ca}^{++}$channels in endocan- 
nabinoid-mediated long-term depression in the nucleus accumbens. Neuropharmacology 54:87-94.

Melchior JR, Ferris MJ, Stuber GD, Riddle DR, Jones SR (2015) Optogenetic versus electrical stimulation of dopamine terminals in the nucleus accumbens reveals local modulation of presynaptic release. J Neurochem 134:833-844.

Pascoli V, Terrier J, Espallergues J, Valjent E, O'Connor EC, Lüscher C (2014) Contrasting forms of cocaine-evoked plasticity control components of relapse. Nature 509:459-464.

Patton MH, Padgett KE, McKeon PN, Qadir H, Patton MS, Mu C, Roberts BM, Mathur BN (2019) TrkB-dependent disinhibition of the nucleus accumbens is enhanced by ethanol. Neuropsychopharmacology 44: $1114-1122$

Pisansky MT, Lefevre EM, Retzlaff CL, Trieu B, Rothwell PE (2019) Nucleus accumbens fast-spiking interneurons constrain impulsive action. Biol Psychiatry, in press.

Pitman KA, Puil E, Borgland SL (2014) GABA $_{B}$ modulation of dopamine release in the nucleus accumbens core. Eur J Neurosci 40:3472-3480.

Robbe D, Alonso G, Chaumont S, Bockaert J, Manzoni OJ (2002) Role of $\mathrm{P} / \mathrm{Q}-\mathrm{Ca}^{2+}$ channels in metabotropic glutamate receptor 2/3-dependent presynaptic long-term depression at nucleus accumbens synapses. J Neurosci 22:4346-4356.

Robbe D, Alonso G, Manzoni OJ (2003) Exogenous and endogenous cannabinoids control synaptic transmission in mice nucleus accumbens. Ann N Y Acad Sci 1003:212-225.

Roberts DC, Andrews MM (1997) Baclofen suppression of cocaine self-administration: demonstration using a discrete trials procedure. Psychopharmacology 131:271-277.

Rothwell PE, Fuccillo MV, Maxeiner S, Hayton SJ, Gokce O, Lim BK, Fowler SC, Malenka RC, Südhof TC (2014) Autism-associated neuroligin-3 mutations commonly impair striatal circuits to boost repetitive behaviors. Cell 158:198-212.

Scudder SL, Baimel C, Macdonald EE, Carter AG (2018) Hippocampalevoked feedforward inhibition in the nucleus accumbens. J Neurosci 38:9091-9104.

Smith ACW, Scofield MD, Heinsbroek JA, Gipson CD, Neuhofer D, RobertsWolfe DJ, Spencer S, Garcia-Keller C, Stankeviciute NM, Smith RJ, Allen NP, Lorang MR, Griffin WC 3rd, Boger HA, Kalivas PW (2017) Accumbens nNOS interneurons regulate cocaine relapse. J Neurosci 37:742-756.

Solís JM, Nicoll RA (1992) Pharmacological characterization of GABABmediated responses in the CA1 region of the rat hippocampal slice. J Neurosci 12:3466-3472.

Stoppel LJ, Kazdoba TM, Schaffler MD, Preza AR, Heynen A, Crawley JN, Bear MF (2018) R-baclofen reverses cognitive deficits and improves social interactions in two lines of 16p11.2 deletion mice. Neuropsychopharmacology 43:513-524.

Tabata T, Kano M (2006) GABAB receptor-mediated modulation of glutamate signaling in cerebellar Purkinje cells. Cerebellum 5:127-133.

Tabata T, Kano M (2010) GABAB receptor-mediated modulation of metabotropic glutamate signaling and synaptic plasticity in central neurons. Adv Pharmacol 58:149-173.
Tepper JM, Koós T, Ibanez-Sandoval O, Tecuapetla F, Faust TW, Assous M (2018) Heterogeneity and diversity of striatal GABAergic interneurons: update 2018. Front Neuroanat 12:91.

Terunuma M (2018) Diversity of structure and function of $\mathrm{GABA}_{\mathrm{B}}$ receptors: a complexity of $\mathrm{GABA}_{\mathrm{B}}$-mediated signaling. Proc Jpn Acad Ser B Phys Biol Sci 94:390-411.

Tritsch NX, Oh WJ, Gu C, Sabatini BL (2014) Midbrain dopamine neurons sustain inhibitory transmission using plasma membrane uptake of GABA, not synthesis. eLife 3:e01936.

Trouche S, Koren V, Doig NM, Ellender TJ, El-Gaby M, Lopes-Dos-Santos V, Reeve HM, Perestenko PV, Garas FN, Magill PJ, Sharott A, Dupret D (2019) A hippocampus-accumbens tripartite neuronal motif guides appetitive memory in space. Cell 176:1393-1406.e16.

Turner BD, Kashima DT, Manz KM, Grueter CA, Grueter BA (2018a) Synaptic plasticity in the nucleus accumbens: lessons learned from experience. ACS Chem Neurosci 9:2114-2126.

Turner BD, Rook JM, Lindsley CW, Conn PJ, Grueter BA (2018b) mGlu1 and mGlu5 modulate distinct excitatory inputs to the nucleus accumbens shell. Neuropsychopharmacology 43:2075-2082.

Uchimura N, North RA (1991) Baclofen and adenosine inhibit synaptic potentials mediated by gamma-aminobutyric acid and glutamate release in rat nucleus accumbens. J Pharmacol Exp Ther 258:663-668.

Voigt RM, Herrold AA, Riddle JL, Napier TC (2011) Administration of $\mathrm{GABA}_{\mathrm{B}}$ receptor positive allosteric modulators inhibit the expression of previously established methamphetamine-induced conditioned place preference. Behav Brain Res 216:419-423.

Wang X, Gallegos DA, Pogorelov VM, O'Hare JK, Calakos N, Wetsel WC, West AE (2018) Parvalbumin interneurons of the mouse nucleus accumbens are required for amphetamine-induced locomotor sensitization and conditioned place preference. Neuropsychopharmacology 43:953963.

Wells CA, Zurawski Z, Betke KM, Yim YY, Hyde K, Rodriguez S, Alford S, Hamm HE (2012) G $\beta \gamma$ inhibits exocytosis via interaction with critical residues on SNAP-25. Mol Pharmacol 82:1136-1149.

Winters BD, Krüger JM, Huang X, Gallaher ZR, Ishikawa M, Czaja K, Krueger JM, Huang YH, Schlüter OM, Dong Y (2012) Cannabinoid receptor 1-expressing neurons in the nucleus accumbens. Proc Natl Acad Sci U S A 109:E2717-E2725.

Wright WJ, Schlüter OM, Dong Y (2017) A feedforward inhibitory circuit mediated by CB1-expressing fast-spiking interneurons in the nucleus accumbens. Neuropsychopharmacology 42:1146-1156.

Yu J, Yan Y, Li KL, Wang Y, Huang YH, Urban NN, Nestler EJ, Schlüter OM, Dong Y (2017) Nucleus accumbens feedforward inhibition circuit promotes cocaine self-administration. Proc Natl Acad Sci U S A 114: E8750-E8759.

Zurawski Z, Thompson Gray AD, Brady LJ, Page B, Church E, Harris NA, Dohn MR, Yim YY, Hyde K, Mortlock DP, Jones CK, Winder DG, Alford S, Hamm HE (2019) Disabling the G $\beta \gamma$-SNARE interaction disrupts GPCR-mediated presynaptic inhibition, leading to physiological and behavioral phenotypes. Sci Signal 12:eaat8595. 